Georgetown University Law Center

Scholarship @ GEORGETOWN LAW

2015

Priority-Setting, Cost-Effectiveness, and the Affordable Care Act

Govind Persad

Georgetown University, gcp11@georgetown.edu

This paper can be downloaded free of charge from:

https://scholarship.law.georgetown.edu/facpub/1509

http://ssrn.com/abstract=2658205

41 Am. J.L. \& Med. 119 (2015)

This open-access article is brought to you by the Georgetown Law Library. Posted with permission of the author. Follow this and additional works at: https://scholarship.law.georgetown.edu/facpub

Part of the Business Law, Public Responsibility, and Ethics Commons, Health and Medical Administration Commons, and the Insurance Commons 


\title{
Priority Setting, Cost-Effectiveness, and the Affordable Care Act
}

\author{
Govind Persad $^{\dagger}$
}

The Affordable Care Act (ACA) may be the most important health law statute in American history, yet much of the most prominent legal scholarship examining it has focused on the merits of the court challenges it has faced rather than delving into the details of its priority-setting provisions. In addition to providing an overview of the ACA 's provisions concerning priority setting and their developing interpretations, this Article attempts to defend three substantive propositions.

First, I argue that the ACA is neither uniformly hostile nor uniformly friendly to efforts to set priorities in ways that promote cost and quality.

Second, I argue that the ACA does not take a single, unified approach to priority setting; rather, its guidance varies depending on the aspect of the healthcare system at issue (Patient Centered Outcomes Research Institute, Medicare, essential health benefits) and the factors being excluded from priority setting (age, disability, life expectancy).

Third, I argue that cost-effectiveness can be achieved within the ACA's constraints, but that doing so will require adopting new approaches to costeffectiveness and priority setting. By limiting the use of standard cost-effectiveness analysis, the ACA makes the need for workable rivals to cost-effectiveness analysis a pressing practical concern rather than a mere theoretical worry.

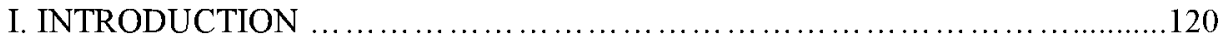

II. PRIORITY SETTING IN MEDICAL CARE …….......................................... 122

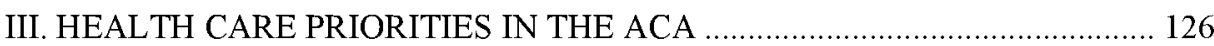

A. THE PATIENT-CENTEREd OutCOMES ReSEARCH INSTITUTE ........................ 129

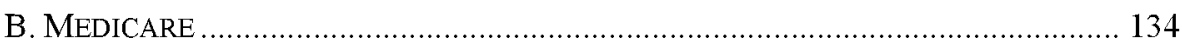

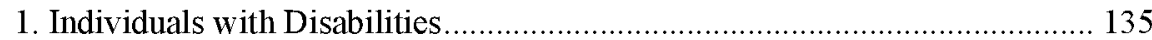

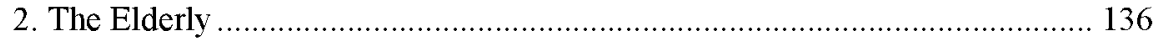

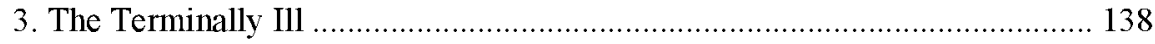

C. EsSEnTIAL Health BenEFITS............................................................. 140

1. Nondiscrimination in Design............................................................ 140

2. Nondiscrimination in Provision.......................................................... 144

$\dagger$ J.D., Stanford Law School; Ph.D. Candidate, Philosophy, Stanford University; Visiting Scholar, 2013-14, Department of Medical Ethics and Health Policy, University of Pennsylvania. Thanks to Alison Hoffman, Wendy Salkin, Andrea Wang, and Kathryn Zeiler for their detailed comments on prior drafts. 
3. Fairness to Diverse Segments of the Population ................................... 147

D. Additional Regulations on Plans OfFERED Through ExchangeS ......... 160

1. Preventing Death at Any Cost ................................................................ 160

2. Clinical Trials and "Life-Threatening Conditions" "................................. 161

III. ACHIEVING COST CONTROL AND QUALITY IMPROVEMENT

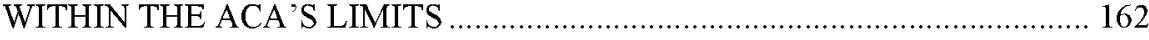

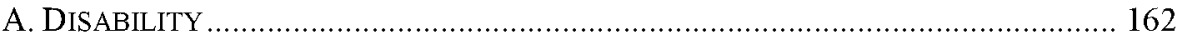

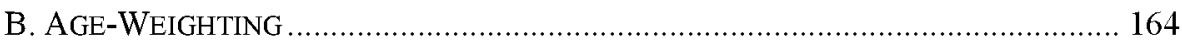

C. FAIRNESS TO DIVERSE SEGMENTS OF THE POPULATION.................................. 165

V. CONCLUSION 165

\section{INTRODUCTION}

In drafting the Affordable Care Act (ACA), policymakers faced delicate and politically explosive tradeoffs between expanding access to medical care and controlling the ever-increasing cost of that care. This Article conducts a detailed examination of several provisions of the ACA, introduced as the ACA traced its tortuous path from introduction to enactment, that limit the healthcare system's use of cost-effectiveness analysis, a technique that quantifies the cost and expected benefit of medical interventions and enables actors within the system to set priorities. ${ }^{1}$

Part I of this Article introduces three representative patients and presents the problem of priority setting in healthcare. Priority setting takes place at a variety of different levels within the healthcare system, ranging from basic science research to federal policy to individual physician-patient interactions. And priority-setting decisions can potentially save-or cost-more lives than even some of the most discussed innovations and mistakes within medical care. ${ }^{2}$

Part II then turns to the text of the ACA, analyzing a variety of provisions that regulate the priority-setting options of different actors in the healthcare system. Part II.A discusses provisions that prevent the Patient Centered Outcomes Research Institute (PCORI) from employing priority-setting approaches that disadvantage people with disabilities. Part II.B discusses similar provisions that restrict the considerations Medicare can employ when making reimbursement or coverage decisions. Part II.C discusses restrictions on priority setting for essential health benefits. Part II.D discusses priority setting for health plans offered through Health Insurance Exchanges. In discussing these provisions, I draw on parallels with both tort and antidiscrimination law. My ultimate concern is that these provisions generate an inconsistent set of priority-setting rules that threaten to hamstring cost control efforts without substantially improving population health.

Part III offers solutions to the challenges that the provisions discussed in Part II pose. Part III.A proposes an approach to cost-effectiveness analysis that avoids disadvantaging people with preexisting disabilities in a manner prohibited by the ACA. Part III.B discusses when considering age in priority setting is and is not appropriate under the ACA. Part III.C discusses how cost-effectiveness analysis can equitably respond to the different healthcare needs of different groups within a

\footnotetext{
${ }^{1}$ See World Health ORG., Who Guide to Cost-EfFectiveness Analysis 3-5 (T. Tan-Torres Edejer et al. eds., 2003) (discussing the basics of cost-effectiveness analysis).

${ }^{2}$ See id. at 84-85 (illustrating how the use of cost-effectiveness analysis can lead to a gain in healthy life expectancy).
} 
population.

In addition to providing an overview of the ACA's provisions concerning priority setting and their developing interpretation, this Article attempts to defend three substantive propositions. First, I argue that the ACA is neither uniformly hostile nor uniformly friendly to priority-setting efforts that promote cost and quality. Second, I argue that the ACA does not take a single, unified approach to priority setting; rather, its guidance varies depending on the aspect of the healthcare system at issue (PCORI, Medicare, essential health benefits) and the factor being excluded from priority setting (age, disability, life expectancy). Third, I argue that cost-effectiveness can be achieved within the ACA's constraints, but only by adopting new approaches to costeffectiveness and priority setting. While several authors have criticized the prevailing cost-effectiveness approaches used in medical contexts as insufficiently sensitive to important normative considerations, ${ }^{3}$ these criticisms have had little force because the prevailing approaches are widely adopted and easy to operationalize. By limiting the use of standard cost-effectiveness analysis, the ACA makes the need for workable rivals to cost-effectiveness analysis a pressing practical concern rather than a mere theoretical worry.

A few commentators on the ACA have noted the provisions I discuss, ${ }^{4}$ as have some commentators on comparative effectiveness and cost-effectiveness in medical care more generally. ${ }^{5}$ Some of these authors regard the ACA's priority-setting provisions as largely or completely precluding the use of cost-effectiveness analysis, ${ }^{6}$ while others regard these provisions as ineffectual window dressing that fails to set meaningful limits on the choices of healthcare decision makers. ${ }^{7}$ Even though prioritysetting provisions affect a wide swath of actors in the healthcare system-ranging from private insurers to administrators to potential litigants challenging insurance decisions-legal scholarship has yet to discuss them at length. In particular, no article has yet discussed the United States Department of Health and Human Services' Final Rule that codifies the ACA's provisions, nor has any discussed the question of how far the ACA extends the antidiscrimination paradigm into the fields of health insurance and medical care. In this Article, I both provide a systematic analysis of these provisions and begin a broader conversation.

\footnotetext{
${ }^{3}$ See, e.g., Christopher J.L. Murray et al., Development of WHO Guidelines on Generalised CostEffectiveness Analysis, 9 HEALTH ECON. 235 (2000), available at http://www.who.int/choice/publications/ p 2000 guidelines generalisedcea.pdf.

${ }^{4}$ See Allison K. Hoffman, Three Models of Health Insurance: The Conceptual Pluralism of the Patient Protection and Affordable Care Act, 159 U. PA. L. REv. 1873, 1905-06 (2011) (arguing that restrictions on priority setting for essential health benefits reflect antidiscrimination commitments); James Dabney Miller, The Patient-Centered Outcomes Research Institute, 4 J. HEALTH \& LIFE SCI. L. 4, 19 (2010) (discussing restrictions on priority setting within PCORI); Richard S. Saver, Health Care Reform's Wild Card: The Uncertain Effectiveness of Comparative Effectiveness Research, 159 U. PA. L. REV. 2147, 2166-67 (2011) (discussing restrictions in the use of comparative-effectiveness research within Medicare).

${ }^{5}$ See Sharona Hoffman \& Andy Podgurski, Improving Health Care Outcomes Through Personalized Comparisons of Treatment Effectiveness Based on Electronic Health Records, 39 J.L. MED. \& ETHICS 425, 428 (2011) (summarizing critics' views of cost-effectiveness research); Nadia N. Sawicki, Patient Protection and Decision-Aid Quality: Regulatory and Tort Law Approaches, 54 ARIZ. L. REV. 621, 641-42 (2012) (discussing cost-effectiveness research and the balance of patient values regarding quality and length of life); Emily S. Stopa, Comment, Harnessing Comparative Effectiveness Research to Bend the Cost Curve and Achieve Successful Health Reform: An Assessment of Constitutional Barriers to Limiting Health Care Treatment Options, 13 U. PA. J. ConsT. L. 815, 832-46 (2011) (discussing potential constitutional challenges to the use of cost-effectiveness analysis in priority setting)

${ }^{6}$ See, e.g., Saver, supra note 4 , at 2168.

${ }^{7}$ E.g., Stephen L. Mikochik, Rationing Human Life: Health Care Reform and People with Disabilities, 26 ISSUES L. \& MED. 199, 204-05 (2011).
} 
More importantly, this Article offers novel positive solutions to the problems that these provisions pose. These solutions have applicability not only for the growing field of legal scholarship surrounding the ACA, but also for empirical and conceptual work on cost-effectiveness more generally. This Article explores alternatives to traditional cost-effectiveness analysis, which could help healthcare priority setting accord better with public preferences as well as with antidiscrimination goals.

\section{PRIORITY SETTING IN MEDICAL CARE}

Imagine three cancer patients:

- $\quad$ Alice, 70, has breast cancer. Untreated, her life expectancy is estimated at five years. Treatment could cure her cancer, but, because of her advanced age, would add only five years to her untreated life expectancy.

- Bill, 60, has metastatic prostate cancer. Untreated, he can expect to live for three months; treatment could add five years to that estimate.

- Caroline, 30, has osteosarcoma of the leg. Untreated, she is expected to live for five more years; treatment would require amputating her leg, but would leave her completely cancer free. She is also hearing impaired.

Priority setting at different sites and different levels within the healthcare system shapes Alice, Bill, and Caroline's options in myriad ways. Choices about priorities at the "micro level"- that is, choices about which specific individuals should receive which treatments ${ }^{8}$-will affect these patients' options in the most obvious way. Principles and procedures for the micro-level allocation of resources have been most vigorously discussed in contexts where resources are absolutely scarce: when physicians on the battlefield are asked to engage in triage, ${ }^{9}$ when a pandemic leads to vaccine shortages,$^{10}$ or when choices must be made about which patient will receive an organ transplant. ${ }^{11}$ However, micro-level rationing also takes place in more mundane

\footnotetext{
${ }^{8}$ For this useful terminology, I draw on, Note, Scarce Medical Resources, 69 COLUM. L. REV. 620, 670-71 (1969).

${ }^{9}$ See, e.g., James F. Childress, Triage in Neonatal Intensive Care: The Limitations of a Metaphor, 69 VA. L. REV. 547, 548 (1983); see also Thomas B. Leary, Comm'r, Fed. Trade Comm'n, Special Challenges for Antitrust in Health Care, Address at a Forum on Antitrust and Health Care (May 15, 2003), in 18 ANTITRUST 23, 25 (2004) ("Triage is still something that is hard for people to contemplate outside a battlefield because of the innate reluctance to acknowledge any limits on the 'value of a human life,' but a market system that tends to give priority to cases where the treatments are most likely to succeed may be better than the alternatives. In fact, for certain special medical procedures, like organ transplants, this seems to be the way treatment is rationed today.").

${ }^{10}$ Examples of statutes addressing priority setting in a pandemic include, 42 U.S.C $\$ 247 \mathrm{~d}-1$ (b) (2012) (discussing the need for "estimates of high priority populations, as determined by the Secretary, in State, local, and tribal jurisdictions in order to inform Federal, State, local, and tribal decision makers during vaccine shortages and supply disruptions") and ARK. CODE ANN. § 20-10-1304(d)(2) (2014) (noting that "during the outbreak of a pandemic disease, the department may enforce vaccine priorities necessary to limit the loss of life among citizens and to contain the spread of the disease"). For scholarly commentary, see Carl H. Coleman, Allocating Vaccines and Antiviral Medications During an Influenza Pandemic, 39 SETON Hall L. ReV. 1111, 1111-12 (2009) and Necia B. Hobbes, Note, Out of the Frying Pan into the Fire: Heightened Discrimination \& Reduced Legal Safeguards When Pandemic Strikes, 72 U. PITT. L. REV. 779 , $810(2011)$.

${ }^{11}$ See 42 U.S.C. $\$ 274(2)$ (B) (2012) (authorizing the Organ Procurement and Transplantation Network to "establish membership criteria and medical criteria for allocating organs and provide to members of the
} 
contexts: physicians' decisions about which tests to order, how much time to spend with a patient, or which treatments to prescribe all reflect judgments about priorities. ${ }^{12}$

Priority setting at other levels of the healthcare system affects patients' options as well. A 1969 student note in the Columbia Law Review makes the point as well as anything since:

The decisions of particular hospitals or doctors in their selection of specific patients for an available treatment-decisions which might be characterized as "micro-allocation"-form only one aspect of medical resource allocation. Equally significant in affecting the ultimate availability and distribution of these resources are the determinations and underlying policies of a wide variety of persons and institutions-public and private alike-who are quite far removed from the immediate context of patient treatment. Congressional appropriations of research funds, the activities of national health organizations, state underwritings of specialized treatment costs, budgetary allocations within federal agencies maintaining public hospital facilities, and the adjustment of coverage by private health insurance companies are some of the activities which are part of the second phase of medical facilities distribution: the process of "macro-allocation."

Much of this priority setting, rather than establishing hard limits on whether a given patient receives a given treatment, operates by affecting the cost and supply of different treatments. Medical insurers may reimburse treatments for different conditions at different rates, ${ }^{14}$ while formularies and practice guidelines may recommend some treatments over others and deny reimbursement for unproven treatments. ${ }^{15}$ Value-based insurance designs, which reduce or eliminate copayments

public an opportunity to comment with respect to such criteria"); Neal R. Barshes et al., Justice, Administrative Law, and the Transplant Clinician: The Ethical and Legislative Basis of a National Policy on Donor Liver Allocation, 23 J. CONTEMP. HEALTH L. \& POL'Y 200, 227 (2007). For a detailed discussion of the principles and systems employed in micro-level rationing of scarce resources, see Govind Persad et al., Principles for Allocation of Scarce Medical Interventions, 373 LANCET 423 (2009)

${ }^{12}$ See Mark A. Hall, Rationing Health Care at the Bedside, 69 N.Y.U. L. REv. 693, 711 -14 (1994)

${ }^{13}$ Scarce Medical Resources, supra note 8, at 670-71.

${ }^{14}$ See TeX. Gov'T CODE ANN. $\S 533.005$ (a)(2) (West Supp. 2014) ("A contract between a managed care organization and the commission for the organization to provide health care services to recipients must contain ... capitation rates that ensure the cost-effective provision of quality health care."); Carrao v. Health Care Serv. Corp., 454 N.E.2d 781, 786 (IIl. App. Ct. 1983) (noting that Illinois state law requires a healthcare service corporation to "make a vigorous, good-faith effort to contain rates of reimbursement to hospitals and other participating health care providers as well as to promote cost-effective alternative forms of health care" (emphasis omitted)).

${ }^{15}$ See FLA. STAT. ANN. \$ 409.91195(8) (West 2013) ("The committee shall develop its preferred drug list recommendations by considering the clinical efficacy, safety, and cost-effectiveness of a product."); KAN. STAT. ANN. § 39-7121a(b) (Supp. 2013) ("[T]he department of health and environment shall evaluate drugs and drug classes to determine whether inclusion of such drugs or drug classes in a starter dose program would be clinically efficacious and cost effective."); MINN. STAT. ANN. § 256B.0625(13)(d) (West 2007) (stating that decision makers considering whether to include treatments in the state's medical assistance formulary should evaluate whether the treatments are "necessary, appropriate, and cost-effective for the treatment of certain specified chronic diseases, conditions, or disorders"); N.M. STAT. ANN. § 27-2C3(A) (West 2011) ("The department shall develop or implement a formulary or preferred drug list, taking into consideration the clinical efficacy, safety and cost-effectiveness of a product."); 32 C.F.R. $\S$ 199.21(c)(1) (2014) (establishing a committee to ensure that, within the TRICARE program, "the selection of pharmacentical agents for the uniform formulary is based on broadly representative professional expertise concerning relative clinical and cost effectiveness of pharmaceutical agents"); see also Russell Korobkin, Comparative Effectiveness Research as Choice Architecture: The Behavioral Law and Economics Solution to the Health Care Cost Crisis, 112 MiCH. L. REV. 523, 549 (2014) ("Many insurance plans come with 
for certain drugs or even pay patients to choose those drugs, may also provide patients with financial incentives to choose specific treatments. ${ }^{16}$ Even more general decisions in the healthcare system-such as which specialties prospective physicians are encouraged to pursue-also ultimately affect patients' access to care. ${ }^{17}$

Priority-setting decisions can markedly affect the ability of the healthcare system to save lives, cure illness, and improve patients' quality of life. Directing resources toward treatments that save more lives and cure more illnesses has had, in many cases, a greater impact than the discovery of a new antibiotic or an innovative device. ${ }^{18}$ As the medical ethicist Toby Ord observes:

If we can save one thousand lives with one intervention and ten thousand with another at an equal price, then merely moving our funding from the first to the second saves nine thousand lives. Thus merely moving funding from one intervention to a more cost-effective one can produce almost as much benefit as adding an equal amount of additional funding. ${ }^{19}$

Ord's point is that moving funding from a less cost-effective to a more costeffective intervention can provide almost as much benefit as increasing funding for a more cost-effective intervention by the same amount. But his reasoning additionally suggests that moving funding from a less cost-effective to a more cost-effective intervention could provide more benefit than adding a lesser amount of additional funding, or than making a modest improvement in the efficiency or effectiveness of medical practice.

However, unlike the discovery of new antibiotics or surgical techniques, prioritysetting decisions are frequently controversial. This is because the great gains realized by shifting resources toward more cost-effective interventions entail losses-

pharmaceutical 'formularies,' for example, whereby drugs in more favored coverage 'tiers' require lower patient copayments, and drugs in less favored tiers require higher copayments or are even excluded from coverage altogether.").

${ }^{16}$ See Korobkin, supra note 15 , at $549-50$ ("Using an emerging practice known as value-based insurance design ('VBID'), insurance companies and self-insured employers have experimented with offering reduced or even zero copayments for prescription drugs that, when taken as directed, are particularly likely to reduce future health care costs." (footnotes omitted)); see also 42 U.S.C. $\S 300 \mathrm{gg}-13$ (c) (2012) ("The Secretary may develop guidelines to permit a group health plan and a health insurance issuer offering group or individual health insurance coverage to utilize value-based insurance designs."); D.C. CODE \& 31-3171.16(a)(1)(A)(i)(IX) (2001) (stating that the D.C. health exchange's advisory board should evaluate whether the exchange should employ a "[v]alue-based insurance design"); Public Comment Letter from Mark J. Ugoretz, President, ERISA Indust. Comm., to the Internal Revenue Service (Sept. 8, 2010) (on file with the Federal eRulemaking Portal), available at http://www.regulations.gov/\#! documentDetail;D=IRS-2010-0017-0003 (noting that the ERISA Industry Committee "strongly supports the provisions that promote value-based insurance designs by permitting plans to impose cost-sharing requirements on out-of-network services").

${ }^{17}$ See MD. CODE ANN., EduC. § 18-2805(b) (LexisNexis Supp 2014) (directing the office responsible for student loan repayment assistance to "prioritize funding for the repayment of education loans" to physicians practicing in underserved geographic areas or underserved specialties); VA. CODE ANN. § 32.1122.6:1 (Supp. 2014) (similar state code); see also Ann Marie Marciarille, Healing Medicare Hospital Recidivism: Causes and Cures, 37 AM. J.L. \& MED. 41, 69 (2011) ("The shortage of primary care physicians is itself partly a payment systems failure that rewards specialists with much higher incomes-and concomitantly much higher professional status-than that accorded primary care physicians."); Thomas Wm. Mayo, Nonfinancial Barriers to Health Care, 32 Hous. L. REV. 1187, $1188-89$ (1996) (discussing how geographic and specialty mal-distribution among Texas physicians presents a barrier to healthcare access).

${ }^{18}$ See Toby Ord, The Moral ImPerative Toward Cost-EFfectiveness in Global HeAlth 7 (2013), available at www.cgdev.org/content/publications/detail/1427016 (illustrating the magnitude of the impact that reallocation of resources can have on saving lives).

${ }^{19} \mathrm{Id}$. 
sometimes substantial losses-for those who benefited from the less cost-effective interventions. ${ }^{20}$ Put differently, priority-setting decisions, unlike medical innovations, are not Pareto improvements. ${ }^{21}$ Those who believe they will lose under a given priority-setting regime frequently organize to oppose that change, even when their victory leads to a less effective healthcare system. ${ }^{22}$ Consider, for example, Ord's suggestion that the money spent on providing surgical treatment for Kaposi's sarcoma, a cancer associated with AIDS, could save far more lives if instead spent on expanding access to antiretroviral treatments for HIV-infected individuals. ${ }^{23} \mathrm{~A}$ proposal to put Ord's suggestion into practice would almost certainly draw fire from those who have a stake in continued public funding for the treatment of Kaposi's sarcoma: patients with the condition, surgeons specializing in its treatment, and associated advocacy organizations. This coalition might mobilize to entrench funding for Kaposi's sarcoma treatment and safeguard it against attempts to shift resources toward more costeffective treatments, just as other groups-such as breast cancer patients, ${ }^{24}$ back surgeons, ${ }^{25}$ and Medicare recipients ${ }^{26}$ - now do. Indeed, breast cancer advocacy groups have already succeeded in entrenching access to mammograms in the ACA, despite research calling mammography's clinical effectiveness into doubt. ${ }^{27}$ That priority setting in medical care is more difficult to implement than innovation mirrors similar phenomena elsewhere: while efforts to eliminate government fraud and abuse are

${ }^{20} \mathrm{Id}$. at $4-5$

21 See, e.g., Willingham v. NovaStar Mortgage, Inc., No. 04-CV-2391, 2006 WL 6676801, at *19 (W.D. Tenn. Feb. 7, 2006) ("Pareto efficiency (or optimality) occurs when no individual can be made better off without making another worse off."); Stephen E. Ellis \& Grant M. Hayden, The Cult of Efficiency in Corporate Law, 5 VA. L. \& BUS. REV. 239, 241-42 (2010) ("A situation $x$ is a Pareto improvement over a situation $y$ just in case no one (strictly) prefers $\mathrm{y}$ to $\mathrm{x}$ and at least one person (strictly) prefers $x$ to $y$... The uncontested nature of Pareto improvements is what makes them so appealing to economists. So long as a given situation is a Pareto improvement over what preceded it, one never has to balance one person's gains in satisfaction with another's losses ...." (footnote omitted)).

${ }^{22}$ Cf. Timothy Stoltzfus Jost \& Sandra J. Tanenbaum, Selling Cost Containment, 19 AM. J.L. \& MED. 95, 95 (1993) ("As long as the health care system reform debate is cast as a zero-sum game, under which the current 'winners' in health care will either continue to 'win' or become 'losers,' the concentrated special interests that benefit from high health care costs will continue to obstruct change.").

${ }^{23}$ ORD, supra note 18 , at 2 .

${ }^{24}$ See Nan D. Hunter, Rights Talk and Patient Subjectivity: The Role of Autonomy, Equality, and Participation Norms, 45 WAKE FOREST L. REV. 1525, 1543 (2010) (noting that "advocates obtained . . . [a] provision in legislation that established breast cancer research in the Department of Defense ('DoD'), a location that insulated it from cuts in domestic funding that customarily exempted DoD.").

${ }^{25}$ See Sofamor Danek Grp. v. Gaus, 61 F.3d 929, 931 (D.C. Cir. 1995) (challenging federal clinical practice guidelines), cert. denied, 516 U.S. 1112 (1996); Eleanor D. Kinney, Behind the Veil Where the Action Is: Private Policy Making and American Health Care, 51 ADMIN. L. REv. 145, 167 (1999) (detailing Congress's efforts to defund the agency responsible for promulgating clinical practice guidelines on treatment of back pain).

${ }^{26}$ See April M. Elliott, Note, Medicare as Technology Regulator: Medicare Policy's Role in Shaping Technology Use and Access, 26 BERKELEY TECH. L.J. 1489, 1506-07 (2011) (noting that "changes to the fundamental nature of Medicare and to the guarantee of coverage it provides to millions of beneficiaries are widely considered politically infeasible"); see also Michael F. Cannon, Pay-for-Performance: Is Medicare a Good Candidate?, 7 YALE J. HEALTH POL'Y L. \& ETHICS 1, 31 -32 (2007) ("Given the influence that Medicare's P4P decisions would have on providers' incomes and the overall tax burden, those interest groups can be expected to use political pressure to block changes that they expect would adversely affect their interests.").

${ }^{27} 42$ U.S.C. $\$ 300 \mathrm{gg}-13(\mathrm{a})(5)$ (2012) ("[F]or the purposes of this chapter, and for the purposes of any other provision of law, the current recommendations of the United States Preventive Service Task Force regarding breast cancer screening, mammography, and prevention shall be considered the most current other than those issued in or around November 2009."); see also Jessica Mantel, Setting National Coverage Standards for Health Plans Under Healthcare Reform, 58 UCLA L. REV. 221, 246 (2010) (noting that "the Senate quickly amended their healthcare reform bill to include a provision guaranteeing coverage of annual mammograms for women age forty and over"). 
broadly popular, proposals to replace existing programs with more efficient alternatives frequently meet vigorous opposition from those who would lose out due to the change. ${ }^{28}$

The ACA, perhaps in recognition of the political power particular interest groups wield, contains no "death panels" 29 or "God Committees" for micro-level allocation, or that directly deny Alice, Bill, or Caroline access to treatment. Nonetheless, the ACA's provisions substantially affect the priorities that physicians, insurers, and other actors in the healthcare system pursue. By establishing which priority-setting factors may be used in establishing the list of essential health benefits, ${ }^{31}$ the ACA shapes the landscape of medical care: if a category of treatments is defined as an essential health benefit, that category of treatments will be provided in every plan that is a "qualified health plan" under the ACA. ${ }^{32}$ The same is true when the ACA sets standards for which factors can be employed in priority setting within Medicare. ${ }^{33}$ The ACA also establishes-and establishes priority-setting standards for-the PCORI, which researches the comparative effectiveness of different treatments and publicizes its findings, thereby providing physicians and insurers with an important resource when setting priorities. ${ }^{34}$ And the ACA regulates plans offered through government-established Health Insurance Exchanges ("Exchanges") in other ways; for instance, the ACA requires plans to permit enrollees to participate in certain clinical research trials. ${ }^{35}$

Part II discusses in more detail these provisions of the ACA, which explicitly set healthcare priorities, or - more frequently—prohibit decision makers from considering certain factors when setting priorities.

\section{HEALTH CARE PRIORITIES IN THE ACA}

Many aspects of the ACA simply attempt to improve cost, quality, or access to healthcare for patients across the board, by increasing funding or focusing resources on

\footnotetext{
${ }^{28}$ See Corinna Sorenson et al., The Politics of Comparative Effectiveness Research: Lessons from Recent History, 39 J. HEALTH POL. POL'Y \& L. 139, 153 (2014) (“[I]n both the United States and abroad, a public backlash has occurred when available evidence calls for some degree of disinvestment or places conditions on access to or payment for care. In such cases, the research (and general overall approach) is seen as a potential threat to the interests of vested stakeholders, namely, organized medicine, industry, and patient advocacy organizations-groups who typically possess significant resources to influence policy makers."); cf. David A. Hyman. Convicts and Convictions: Some Lessons from Transportation for Health Reform, 159 U. PA. L. REV. 1999, 2024 (2011) (quoting Laura Meckler, Obama's Health Expert Gets Political, WaLl ST. J., July 24, 2009, at Al) ("Officials had been trying for years to cut payments to suppliers of oxygen and other medical equipment, which critics say are inflated. Yet when a new competitive bidding process was set to take effect last year, industry supporters in Congress were able to delay the plan. They are still fighting to block changes.").

${ }^{29}$ See Bank of America Corp., SEC No-Action Letter, 2011 WL 87736 (Mar. 7, 2011) (discussing the "protests over 'death panels' that supposedly would result from health care reform legislation"); Abigail R. Moncrieff, The Freedom of Health, 159 U. PA. L. REV. 2209, 2239-41 (2011) (recapping the "death panels" debate).

${ }^{30}$ See Sallie Thieme Sanford, What Scribner Wrought: How the Invention of Modern Dialysis Shaped Health Law and Policy, 13 RICH. J.L. \& PUB. INT. 337, 341-42 (2010) (discussing how a committee responsible for selecting patients to receive life-saving treatment was dubbed the "God Committee").

${ }^{31} 42$ U.S.C. $\$ 18022(2012)$

32 U.S.C. $\$ 18021($ a)(1)(B).

${ }^{33}$ See 42 U.S.C. $\$ 1320 \mathrm{e}-1(\mathrm{c})-(\mathrm{e})$.

3442 U.S.C. $\$ 1320 \mathrm{e}(\mathrm{b})-(\mathrm{d})$.

3542 U.S.C. $\$ 300 \mathrm{gg}-8$ (d)(1) ("'[A]pproved clinical trial' means a phase I, phase II, phase III, or phase IV clinical trial that is conducted in relation to the prevention, detection, or treatment of cancer or other lifethreatening disease or condition.").
} 
preventing fraud and waste. ${ }^{36}$ Although these aspects may incidentally affect priority setting, their focus is not the distribution of benefits among patients. ${ }^{37}$

This Article, in contrast, concentrates on provisions in the ACA that explicitly prohibit or require certain forms of priority setting, and thereby affect the comparative priority that specific health conditions-like those of Alice, Bill, and Carolinereceive in the healthcare system. The provisions I discuss in this Part pertain to four different aspects of the healthcare system that the ACA establishes or affects: PCORI, Medicare, essential health benefits, and the Exchanges. These provisions restrict the use of four different health factors for priority setting: disability, age, life expectancy, and imminence of death. ${ }^{38}$

\begin{tabular}{|l|l|l|l|l|}
\hline & Disability & Age & $\begin{array}{l}\text { Future Life } \\
\text { Expectancy }\end{array}$ & $\begin{array}{l}\text { Imminence of } \\
\text { Death }\end{array}$ \\
\hline PCORI & Prohibited & Permitted & Permitted & Permitted \\
\hline Medicare & Prohibited & Prohibited & Prohibited & Permitted \\
\hline $\begin{array}{l}\text { Essential Health } \\
\text { Benefits }\end{array}$ & Prohibited & Prohibited & Prohibited & Permitted \\
\hline Exchange Plans & Neutral & Neutral & Neutral & Required \\
\hline
\end{tabular}

I divide my discussion below into four subparts, focusing on PCORI, Medicare, essential health benefits, and Exchanges, respectively. I choose this organization, rather than organizing my discussion by health factor, in order to emphasize that the ACA issues different guidelines to different actors within the healthcare system. That the ACA directs one actor, like PCORI, to consider or ignore a given healthcare factor when setting priorities does not entail that it gives the same direction to another actor, like Medicare.

Interestingly, many of the provisions in the ACA that prohibit or require certain forms of priority setting represent an unusual consensus among a variety of actors in the healthcare system. Many were added through efforts by conservative Senators who opposed the ACA, such as Michael Enzi of Wyoming, and conservative lobbying organizations such as the National Committee on the Right to Life. ${ }^{39}$ Yet they have been embraced by many more moderate and liberal causes, such as patient advocacy groups and advocates for persons with disabilities. ${ }^{40}$ They have also met approval from

${ }^{36}$ E.g., 42 U.S.C. $\$ \S 300$ gg- 17 to -18 (designating the subheadings as "Ensuring the quality of care" and "Bringing down the cost of health care coverage," respectively).

${ }^{37}$ See 42 U.S.C. $\$ 300 \mathrm{gg}-17$.

${ }^{38}$ See 42 U.S.C. $\$ 1320$ e-1(c)(1) ("The Secretary shall not use evidence or findings from comparative clinical effectiveness research conducted under section $1320 \mathrm{e}$ of this title in determining coverage, reimbursement, or incentive programs under subchapter XVIII of this chapter in a manner that treats extending the life of an elderly, disabled, or terminally ill individual as of lower value than extending the life of an individual who is younger, nondisabled, or not terminally ill."); 42 U.S.C. $§ 18022$ (b)(4)(B) (listing the required elements for consideration in defining essential health benefits); 42 U.S.C. $\$ 18031(\mathrm{e})(1)(\mathrm{B})(\mathrm{iii})$ (explaining how an Exchange may certify a health plan as a qualified health plan).

${ }^{39}$ See John K. Iglehart, The Political Fight over Comparative Effectiveness Research, 29 HEALTH AFF. 1757, 1758 (2010); Sorenson et al., supra note 28, at 142 (discussing Republican opposition to "considerations of cost or cost-effectiveness in the research").

${ }^{40}$ E.g., 156 Cong. Rec. E462-63 (daily ed. Mar. 23, 2010) (statement of Rep. Pascrell) (describing some of the restrictions as "strong protections that will help ensure that the essential health benefits package ... will take into account the needs of people with brain injury and other disabilities . . and not impose value judgments about disability and quality of life."); SARA ROSENBAUM ET AL., THE ESSENTIAL HEALTH BENEFITS PROVISIONS OF THE AFFORdABle CARE ACT: IMPLICATIONS FOR PEOPLE WITH DisABILITIES 9 (2011) ("The Affordable Care Act's essential benefits nondiscrimination provisions break new ground in how to think about . . . common techniques of health benefit design and management-adding new 
industry groups. ${ }^{41}$ This complicates any sort of purposive or public meaning interpretation of these provisions. Looking to the intent of the legislators who introduced the provision might suggest an interpretation in line with conservative objections to cost-effectiveness, which have emphasized concerns about ill peopleparticularly the elderly - being deprived of opportunities to access costly, last chance treatments. ${ }^{42}$ The public understanding of the statute, however, suggests that these provisions also benefited from support on more traditionally liberal grounds. These grounds include concerns about health insurers cherry-picking healthy patients, about the fair treatment of people with disabilities, and about ensuring that the health benefits offered through the ACA were valuable to a diverse cross section of the population. ${ }^{43}$

Some have argued that the provisions I will discuss below in fact place few meaningful restrictions on the use of standard methods of priority setting, such as the use of quality-adjusted life years. ${ }^{44}$ This argument has come both from those enthusiastic about the believed lack of restriction and those concerned about it. Stephen Mikochik argues that the ACA broadly permits priority-setting methods that disadvantage people with disabilities:

Of the numerous instances where the Act authorizes adoption of quality measures, in one case only is the Secretary of Health and Human Services expressly forbidden from relying on comparative clinical effectiveness research that discounts the lives of disabled people. No comparable limit prevents the use of such research in developing best practices for the delivery of health care services. Even in formulating a national health care strategy, the Secretary is not prohibited from

dimensions to prior federal laws regulating insurance and health plans and barring discrimination."); CONSORTIUM FOR CITIZENS WITH DISABILITIES, IOM ESSENTIAL HEALTH BENEFITS SURVEY RESPONSES 10 (praising the restrictions on considering disability within comparative effectiveness research as "very powerful language that is designed to ensure that normative judgments about the quality of life of a person with a disability are not used against people with disabilities when decision makers determine the essential benefits package"); Letter from the Habilitation Benefits Coal., to Marilyn Tavenner, Adm'r, Ctrs. for Medicare \& Medicaid Servs. (Feb. 21, 2013) (on file with the Children's Hospital Association), available at http://www.aahd.us/wp-content/uploads/2013/02/HABCoalitonLtrMedicaid02212013.pdf (similar); Letter from Susan Henderson, Exec. Dir., Disability Rights Educ. \& Def. Fund, to Kathleen Sebelius, Sec'y, U.S. Dep't of Health \& Hum. Servs. (Feb. 14, 2012) (on file with author) (similar).

${ }^{41}$ Letter from Orthotic \& Prosthetic Alliance, to Gary Cohen, Dir., Ctr. for Consumer Info. \& Ins. Oversight (Dec. 26, 2012) (on file with author), available at available at http://Www.oandp.org/assets/PDF/EHB_Comments_D0454932-2.pdf. (endorsing prohibition on excluding coverage for services based on age, disability, or length of life); Press Release, Pharmaceutical Research \& Mfrs. of Am., Statement of the Pharmaceutical Research and Manufacturers of America Supporting Oregon SB 1565 (Jan. 30, 2014) (on file with author), available at http://web.archive.org/web/ 20150323175516/https://olis.leg.state.or.us/liz/2014R1/Downloads/CommitteeMeetingDocument/32029

("The Pharmaceutical Research and Manufacturers of America (PhRMA) and its member companies strongly support the provisions of federal law that prevent discrimination based on age, expected length of life, present or predicted disability, degree of medical dependency or quality of life.")

${ }^{42}$ Cf. John A. Robertson, Cruzan and the Constitutional Status of Nontreatment Decisions for Incompetent Patients, 25 GA. L. REV. 1139, 1140 (1991) ("From the vitalist perspective, all human life is viewed as worthy of protection regardless of its quality or functional ability.").

${ }^{43}$ See Henry J. Kaiser Family Found., Kaiser Health Tracking Poll: March 2013, 8-9 (2013), available at http://kff.org/health-reform/poll-finding/march-2013-tracking-poll/; ROSENBAUM ET AL., supra note 40, at 3-4, 11-12; Michael Saks, What Do Polls Really Tell Us Care Act?, HEALTH AFF. BLOG (Sept. $21, \quad 2012, \quad 11: 42 \quad \mathrm{AM}$ ), $\mathrm{http}: / /$ healthaffairs.org/blog/2012/09/21/what-do-polls-really-tell-us-about-thepublics-view-of-the-affordable-care-act/.

${ }^{44}$ See, e.g., Nicholas Bagley, Bedside Bureaucrats: Why Medicare Reform Hasn't Worked, 101 GEO. L.J. 519,574 (2013) ("As a practical matter, none of the Medicare-specific prohibitions appear all that constraining."); Mikochik, supra note 7, at 204-05. 
incorporating the findings of biased research when addressing gaps in comparative effectiveness information. ${ }^{45}$

Mikochik views this broad permission as catastrophic, and argues for additional regulation. ${ }^{46}$ Meanwhile, Nicholas Bagley agrees with Mikochik that the ACA places few restrictions on the use of cost-effectiveness analysis, but regards this as a desirable feature of the $\mathrm{ACA}^{47}$ Others have argued that the ACA substantially limits or entirely prohibits the use of cost-effectiveness analysis in the healthcare system. ${ }^{48}$

The truth is somewhere in between. The ACA does place substantial limitations on the use of traditional cost-effectiveness analysis by certain actors in the healthcare system, and also fails to remove the limitations that other laws-most notably the Americans with Disabilities Act (ADA)-may place on cost-effectiveness analysis, particularly on methods that employ quality-adjusted life years (QALY) as a metric. But the ACA is not invariably hostile to the use of cost-effectiveness or comparative effectiveness information, so long as these approaches are employed without considering certain factors in a prohibited way. ${ }^{49}$ Furthermore, different sections of the ACA limit the use of cost-effectiveness information in different ways. The limitations on the use of cost-effectiveness information to set essential health benefits, for instance, are more restrictive than the limitations on its use in PCORI or in Medicare. ${ }^{50}$ I turn now to a discussion of these individual sections.

\section{A. The PATIENT-Centered OutComes ResearCh InstiTute}

The ACA establishes, and provides funding for, the PCORI. ${ }^{51}$ PCORI is a nonprofit corporation whose core aim "is to assist patients, clinicians, purchasers, and policy-makers in making informed health decisions." ${ }^{22}$ The ACA directs PCORI to pursue that aim by researching the comparative risks and benefits of different treatments, and by disseminating its research findings to healthcare decision makers. ${ }^{53}$ PCORI does not issue mandates; rather, it provides information that decision makers can rely on as they set priorities. ${ }^{54}$

Although PCORI has been praised as a potential lever to limit high-cost, lowbenefit care, ${ }^{55}$ the ACA limits the approach to priority setting that PCORI can take. Although the initial draft of the ACA authorized PCORI to assess "efficiency and value (including the full range of harms and benefits, such as quality of life), ${ }^{, 56}$ this

${ }^{45}$ Mikochik, supra note 7 , at 204-05.

${ }^{46} I d$. at 205.

${ }^{47}$ Bagley, supra note 44 , at 574 .

${ }^{48}$ E.g., Barry R. Furrow, Cost Control and the Affordable Care Act: CRAMPing Our Health Care Appetite, 13 NEV. L.J. 822, 853 (2013); Lawrence O. Gostin et al., Restoring Health to Health Reform: Integrating Medicine and Public Health to Advance the Population's Well-Being, 159 U. PA. L. REV. 1777 1779 (2011); Elizabeth Weeks Leonard, Death Panels and the Rhetoric of Rationing, 13 NEV. L.J. 872, 885 (2013); Sorenson et al., supra note 30, at 142 (" $[\mathrm{T}]$ he bill language prohibited the use of quality -adjusted life years (QALYs), a metric used in cost-effectiveness to measure net health gain.").

${ }^{49}$ Thomas J. Parisi, How Much Did You Pay for Your Heart: Is a Centralized Entity Performing Health Technology Assessment with Cost-Effectiveness Analysis the Answer to the Rising Costs of Health Care?, 49 JURIMETRICS 285, 299 (2009).

${ }^{50}$ See Furrow, supra note 48 , at 853 .

${ }^{51} 42$ U.S.C. $\$ 1320 \mathrm{e}(\mathrm{b})(2012)$

${ }^{52} 42$ U.S.C. $\$ 1320 \mathrm{e}(\mathrm{c})$.

${ }^{53} 42$ U.S.C. $\$ 1320 \mathrm{e}(\mathrm{d})(1)(\mathrm{A})$.

${ }^{54} 42$ U.S.C. $\$ 1320 \mathrm{e}(\mathrm{b})$.

${ }^{55}$ See Barry R. Furrow, Regulating Patient Safety: The Patient Protection and Affordable Care Act, 159 U. PA. L. REV. 1727, 1738-39 (2011).

${ }^{56}$ James Dabney Miller, The Patient-Centered Outcomes Research Institute, 4 J. HEAL TH \& LIFE SCI. 
mandate disappeared in the final version of the ACA. ${ }^{57}$ Instead, 42 U.S.C. $\S 1320 \mathrm{e}-$ 1(e) mandates that, PCORI "shall not develop or employ a dollars-per-quality adjusted life year (or similar measure that discounts the value of a life because of an individual's disability) as a threshold to establish what type of healthcare is cost effective or recommended." 58

Many commentators have worried that section 1320e-1(e) eviscerates PCORI's ability to engage in any sort of analysis that considers costs as well as comparative effectiveness. ${ }^{59}$ Barry Furrow, for example, argues that this section of the statute imposes "a prohibition on cost-effectiveness calculations" on PCORI, and "appears to explicitly block study of a treatment's cost-effectiveness." ${ }^{\circ 0}$ Elizabeth Weeks Leonard similarly notes that "PCORI is prohibited from generating QALY data, which commercial insurers, providers, and patients might use to compare cost effectiveness of treatment alternatives just as the President envisioned." ${ }^{\prime 1}$ And Larry Gostin and his co-authors note, "the final law inhibits the use of quality cost-effectiveness analysis in coverage, reimbursement, and incentive structures." ${ }^{.62}$ I will argue that the ACA's limitation on the use of QALYs within PCORI does not announce a broad opposition to consideration of costs in priority setting, but rather pursues a more narrow aim: to ensure that patients with preexisting disabilities (like our osteosarcoma patient Caroline) are not disadvantaged in priority-setting decisions on the basis of the effect of their preexisting disability on their future quality of life.

Although the statute establishing PCORI defines several other terms,${ }^{63}$ it does not define a "quality-adjusted life year." ${ }^{\text {"H4 }}$ However, QALYs are widely used by health economists when assessing the benefit of a medical or public health intervention or the burden of an illness, ${ }^{65}$ and have been proposed for use by agencies as well. ${ }^{66}$ As John La Puma notes, "QALYs attempt to combine expected survival with expected quality of life into a single number: if an additional year of healthy life expectancy is worth a value of one (year), then a year of less healthy life expectancy is worth less than one (year). ${ }^{67}$ For example, if amputating Caroline's leg to protect her from osteosarcoma will extend her life by fifty years, but will reduce her quality of life during those additional years to $70 \%$ of a fully healthy person's quality of life, then a QALY

L. 4,19 (2010) (quoting Patient-Centered Outcomes Act of 2009, S. 1213, 11 lth Cong. $§ 2(a)$ (2009)).

${ }^{57}$ Id; ; see 42 U.S.C $\$ 1320 \mathrm{e}-1(\mathrm{e})(2012)$.

${ }^{58} 42$ U.S.C. $\$ 1320 \mathrm{e}-1(\mathrm{e})$.

${ }^{59}$ See sources cited supra note 48.

${ }^{60}$ Furrow, supra note 48 , at 853 .

${ }^{61}$ Leonard, supra note 48 , at 885.

${ }^{62}$ Gostin et al., supra note 48 , at 1779

${ }^{63}$ See 42 U.S.C. $\$ 1320$ e(a) (2012)

${ }^{64}$ See id.

${ }^{65}$ See, e.g., C.C. Earle et al., Systematic Overview of Cost-Utility Assessments in Oncology, $18 \mathrm{~J}$ CLINICAL ONCOLOGY 3302, 3302-03 (2000).

${ }^{66}$ H.R. 2101, 112th Cong. $\$ 39900(b)(1)$ (2013) (proposing "a Center of Eating Disorders Epidemiology for the purpose of," inter alia, "collecting and analyzing information on the effects of eating disorders on quality of life, including disability adjusted life years (DALY) and quality-adjusted life years"); OfFice of MGMT. \& BUdget, EXEC. OfFice of the PREsident, OMB CIRCULAR No. A-4, Regulatory ANALYSIS (2003) (discussing comprehensive, integrated measures of effectiveness such as the number of equivalent lives (ELs) saved and the number of QALYS saved). International organizations use a similar measure, the disability-adjusted life year (DALY), to make funding and practice recommendations for medical care worldwide. See, e.g., Nuria Homedes, The Disability-Adjusted Life Year (DALY) Definition, Measurement and Potential Use 1 (World Bank, Human Capital Working Paper No. 16128, 1996), available at http:/documents.worldbank org/curated/en/1996/07/696380/disability-adjusted-life-year-daly-definitionmeasurement-potential-use.

${ }^{67}$ John La Puma, Quality-Adjusted Life Years: Ethical Implications and the Oregon Plan, 7 Issues L. \& MED. 429, 429 (1992) 
approach will evaluate the procedure as providing thirty-five QALYs (fifty life years at a quality of life of 0.7 ).

The appeal of the QALY is that it provides a single, unified way of accounting for the effects of medical interventions on both quality and length of life. As Matthew Adler has noted, a variety of administrative agencies have recently employed QALYs, or related units of measurement that consider an intervention's effect on both quality and length of life, when making regulatory decisions:

The FDA, over the last half-decade or so, has repeatedly relied on QALYs in its rulemakings .... [T] he EPA has experimented with the so-called "value of statistical life year" (VSLY) approach to monetizing mortality, an approach closely related to QALYs. . . The HHS, in a recent rulemaking facilitating flu and pneumonia vaccinations, cited the cost-effectiveness of these vaccinations in promoting "year[s] of healthy life," a synonym for a QALY. The Office of Management and Budget's (OMB) current guide for Executive Order 12,866, which requires formal regulatory analyses of major rules, stipulates that these documents must include a cost-effectiveness analysis in the case of rules targeted at public health and safety, and it gives a qualified endorsement to QALYs as an appropriate effectiveness metric. The Public Health Service's "Healthy People" initiative, an informational program which measures progress towards public health goals, employs QALYs as one of its key metrics. ${ }^{68}$

The ACA's explicit rejection of the use of QALYs diverges from the programs Adler mentions, and raises the question of what lies behind the ACA's choice not to employ a QALY approach.

Determining how much a given disability detracts from quality of life is often done by employing a "time trade-off" design, where people are asked how much future life they would give up in order to live that future life without disability. ${ }^{69}$ Such time trade-off questions can be posed both to non-disabled and disabled people: nondisabled people could be asked how much extra life would compensate for suffering a disability, while disabled people could be asked how much life they would give up in order to be cured of a disability. However, time trade-offs arguably confuse two types of questions: what ethicists call "axiological questions" (questions about which options produce the most benefit), and what they call "deontic questions" (questions about which options we ought to choose). ${ }^{70}$ That Caroline regards forty-five years of life without a hearing impairment as personally preferable to fifty years of life with a hearing impairment does not entail that she regards it as good public policy to disadvantage someone with an incurable hearing impairment when deciding who should receive life-extending treatment. Yet QALY approaches give lower priority to extending the lives of already disabled people. This objection to QALYs may have found expression - in dicta - in one recent case, where the D.C. Circuit suggested that cost-effectiveness analysis should adopt an approach that, for policy purposes, treats disadvantages imposed on people with preexisting disabilities the same as disadvantages imposed on people without disabilities, even if the existence of a

\footnotetext{
${ }^{68}$ Matthew D. Adler, QALYs and Policy Evaluation: A New Perspective, 6 YALE J. HEALTH POL'y L. \& EтнісS 1, 4-6 (2006).

${ }^{69} \mathrm{Id}$. at $1-3$.

${ }^{70}$ For this distinction, see, for example, Dale Jamieson, Climate Change, Consequentialism, and the Road Ahead, 13 CHI. J. INT'L L. 439, 458 (2013).
} 
preexisting disability means that the disadvantage does not result in as great a change in well-being. ${ }^{71}$

The ACA's reason for prohibiting PCORI from using QALYs as a threshold reflects this concern. The language of section $1320 \mathrm{e}-1(\mathrm{e})$, which refers not only to QALYs but also to any "similar measure that discounts the value of a life because of an individual's disability," general prohibition on the use of any method of measurement that treats extending a person's life as a lower priority when that person suffers from a disability than when she does not.

While PCORI does not make direct prescriptions about which individual patients should receive care, permitting PCORI to use QALYs could disadvantage persons with disabilities in at least two ways. First, other actors in the healthcare system might rely on PCORI's QALY-based recommendations when setting priorities for coverage, reimbursement, or incentives. For instance, life-extending treatments for people who frequently have other comorbidities might receive lower priority than life-extending treatments offered to healthy people. Second, PCORI-as a creation of federal lawmight expressively indicate a governmental endorsement of the view that extending the life of people with disabilities is a lower priority than extending the lives of others.

The objection that the ACA disadvantages people with disabilities is ambiguous in at least one important way. Return to the two ways that QALYs consider the quality of life that treating Caroline would produce. First, they consider limitations on quality of life that result from disabilities - such as her hearing impairment-that preexist the treatment she receives. Second, they consider limitations that result from disabilities, such as an amputated leg, that treating her would cause. When responding to Oregon's use of QALYs in Medicaid, HHS also identified the consideration of disabilities caused by treatment as objectionable, arguing that the Oregon plan, by giving higher priority to treatments that improved quality of life as well as extending life than to treatments that extended life without improving quality, disadvantaged people with disabilities. $^{73}$ In contrast, section $1320 \mathrm{e}-1(\mathrm{e})$ explicitly differentiates preexisting disabilities from those that result from treatment, and permits PCORI to consider the way that treatment affects future quality of life:

Nothing in the provisions of, or amendments made by the Patient Protection and Affordable Care Act, shall be construed to limit comparative clinical effectiveness research or any other research, evaluation, or dissemination of information concerning the likelihood that a health care treatment will result in disability. ${ }^{74}$

This "result in disability" provision differentiates the treatment of preexisting disability from that of treatment-caused disability. ${ }^{75}$ It permits PCORI to consider the fact that treating Caroline's osteosarcoma will mean the loss of her leg, even when it directs comparative effectiveness research to ignore the fact that Caroline is antecedently hearing impaired.

\footnotetext{
${ }^{71}$ Am. Trucking Ass'ns v. U.S. Envtl. Prot. Agency, 175 F.3d 1027, 1039 n.5 (D.C. Cir. 1999) (proposing "measuring the seriousness of a pollution-induced health effect by the absolute level of wellbeing that the effect brings about, not by the decrease in level that the effect causes"), aff' $d$ in part, rev'd in part sub nom. Whitman v. Am. Trucking Ass'ns, 531 U.S. 457 (2001).

${ }^{72} 42$ U.S.C. $\$ 1320 \mathrm{e}-1(\mathrm{e})(2012)$.

${ }^{73}$ See Maxwell J. Mehlman et al., When Do Health Care Decisions Discriminate Against Persons with Disabilities?, 22 J. HEALTH POL. POL'Y \& L. 1385, 1396 (1997).

${ }^{74} 42$ U.S.C. $\$ 1320 \mathrm{e}-1(\mathrm{~d})(3)$ (2012).

${ }^{75} \mathrm{Id}$.
} 
Additionally, as I discuss in the next subpart, the "result in disability" provision permits the Medicare program to consider the effect of disability on treatment effectiveness. As such, it would permit consideration of the fact that Bill's terminal cancer would make many treatments ineffective for him. Rather than requiring healthcare priority setting to entirely ignore cost-effectiveness or ignore disability, section 1320e-1(e) rejects a specific aspect of QALY analysis: that QALY-based approaches systematically disadvantage those who are already disabled even when setting priorities for treatment unrelated to their disability. ${ }^{76}$

My approach diverges from Nicholas Bagley's suggestion that PCORI may employ a QALY-based approach, even one that disadvantages people with disabilities, so long as it does not use QALYs as a threshold. Bagley has argued that the ACA permits PCORI to rank treatments by their cost-per-QALY, or to incorporate QALYs as one consideration in a system of priority setting, so long as PCORI's priority-setting arrangement considers other factors as well. ${ }^{77}$ Bagley's suggestion-that QALYs may be used so long as they are not used as a strict threshold ${ }^{78}$ - parallels other efforts to continue considering a controversial factor so long as that factor does not represent the only reason for a given decision. The most obvious parallel is the use of race and ethnicity in employment and admissions decisions. ${ }^{79}$ In Grutter v. Bollinger, the Supreme Court held that while a quota system that requires that a specific number of seats be set aside for minority applicants was constitutionally unacceptable because it permitted race to function as the sole factor determining whether an applicant was admitted, it was acceptable to "consider race or ethnicity more flexibly as a "plus" factor in the context of individualized consideration of each and every applicant." Following Grutter, many universities shifted to holistic review, and were able to continue considering race as part of an effort to ensure a diverse student body. ${ }^{81}$

However, courts and others interpreting the ACA do so in a different context than that of cases like Grutter. Grutter considers whether a state statute can consider race without violating the Constitution, ${ }^{82}$ whereas those interpreting the ACA will be evaluating not whether considering disability status would be unconstitutional, but rather whether doing so is a faithful interpretation of the statute. Cases construing the ADA have resisted allowing disability status to be a disadvantaging factor in employment, even when disability status is not the sole factor underlying the employer's choice. ${ }^{83}$ A recent Sixth Circuit en banc decision established that no federal circuit court now requires, for relief under the ADA, that an employee's disability be the "sole factor" underpinning an employer's decision to fire an employee. ${ }^{84}$ In the Sixth Circuit, relief can now be granted in cases where the disability is a "but for" factor, ${ }^{85}$ while other circuits go further, granting relief in cases where the

${ }^{76} 42$ U.S.C. $\$ 1320 \mathrm{e}-1(\mathrm{e}) ;$ see also Bagley, supra note 44 , at 573-74.

${ }^{77}$ Nicholas Bagley, Who Says PCORI Can't Do Cost Effectiveness?, InCidental ECONOMIST (Oct. 14, 2013, 6:00 AM), http://theincidentaleconomist.com/wordpress/who-says-pcori-cant-do-costeffectiveness/; see also Bagley, supra note 44, at 574.

${ }^{78}$ Bagley, supra note 44 , at 574.

${ }^{79}$ See, e.g., Grutter v. Bollinger, 539 U.S. 306 (2003).

${ }^{80} \mathrm{Id}$. at 334 .

${ }^{81}$ Sung Hui Kim, The Diversity Double Standard, 89 N.C. L. REv. 945, 975 (2011) (noting that "the University of Michigan's undergraduate admissions office hired additional application counselors and readers, at a cost of $\$ 1.8$ million, to move to a system of holistic review of application files.").

${ }^{82}$ Grutter, 539 U.S. at 321-22.

${ }^{83}$ See, e.g., Lewis v. Humboldt Acquisition Corp., 681 F.3d 312, 321 (6th Cir. 2012).

${ }^{84} I d$. at 315 .

${ }^{85} \mathrm{Id}$. at 321 . 
disability is a "motivating factor." ${ }^{-86}$ Although the ACA's treatment of disability is not identical to that of the ADA, cases interpreting the ADA indicate that objections to the use of a factor or procedure that disadvantages people with disabilities can apply even when the disadvantaging factor is only one among many other factors. ${ }^{87}$

Ultimately, although Bagley's employment of the "threshold" language is an inventive attempt to continue using QALYs as one factor among many, I do not believe the "threshold" language decisively establishes that PCORI may use QALYseven as one factor among many-without violating prohibitions on discrimination against people with disabilities. Courts interpreting the "threshold" language may instead construe the statute to prohibit at least some uses of QALYs where QALY factors play a substantial role in the ultimate recommendation. ${ }^{88}$ Furthermore, the sections below indicate that restrictions on the use of QALYs elsewhere in the ACA would prohibit their use-as currently conceived-entirely, at least in some cases, which may lead courts to prohibit PCORI from using QALYs as well. ${ }^{89}$ In contrast, as I will discuss in Part III, adopting a method of cost-effectiveness analysis that avoids disadvantaging people with preexisting disabilities would avoid violating the restrictions that the ACA places on PCORI.

\section{B. MEDICARE}

The ACA also prohibits certain forms of priority setting within the Medicare program. Section 1320e-1(e) provides that Medicare may not use QALYs or similar factors that disadvantage people with preexisting disabilities "as a threshold to determine coverage, reimbursement, or incentive programs." 90 Meanwhile, section $1320 \mathrm{e}-1(\mathrm{c})(1)$ specifies that:

The Secretary shall not use evidence or findings from comparative clinical effectiveness research conducted under section $1320 \mathrm{e}$ of this title [i.e., by PCORI] in determining coverage, reimbursement, or incentive programs under subchapter XVIII in a manner that treats extending the life of an elderly, disabled, or terminally ill individual as of lower value than extending the life of an individual who is younger, nondisabled, or not terminally ill. ${ }^{91}$

Section $1320 \mathrm{e}-1(\mathrm{c})(1)$ requires that three defined groups not be disadvantaged in priority setting within Medicare: the elderly, the disabled, and the terminally ill. ${ }^{92}$ The protection of each group, as I argue next, poses a unique challenge to priority setting. Giving equal priority to people with disabilities limits the use of QALY approaches; giving equal priority to the elderly limits the use of age weighting; and giving equal

${ }^{86} \mathrm{Id}$. at $324-25$ (Clay, J., concurring in part and dissenting in part) (collecting cases).

${ }^{87}$ See id. at $323-35$

${ }^{88}$ Cf. Ogden v. Bureau of Labor, 699 P.2d 189, 191 (Or. 1985) ("If the word 'solely' ... were given its literal meaning, forbidden age discrimination would occur only if age were the "sole factor' in an employment decision, that is to say, only if the employer's explicit or actual policy were to give preference to an older or a younger employee without regard to any other characteristic, qualification, or performance. The commissioner is not bound to so limited a view of the law.").

${ }^{89}$ Cf. Heslop v. Sanderson, 123 S.W.3d 214, 222 (Mo. Ct. App. 2003) (noting "the illogical result that although home schooling could not be considered as the sole factor in determining whether a custodial arrangement was in the child's best interests, it could be considered as a change of circumstance to modify custody").

${ }^{90} 42$ U.S.C. $\$ 1320 \mathrm{e}-1(\mathrm{e})(2012)$.

${ }^{91} 42$ U.S.C. $\$ 1320 \mathrm{e}-1(\mathrm{c})(1)$. Subchapter XVIII is the section of the United States Code that provides the framework for Medicare. 
priority to terminally ill people may —although I argue it ultimately does not-limit the use of any approach that considers a patient's future lifespan.

\section{Individuals with Disabilities}

Section 1320e-1(c)(1) clearly prohibits Medicare from considering additional years of life for a person with disabilities as less valuable than additional years of life for a non-disabled person. ${ }^{93}$ It therefore prohibits the use of QALYs to determine "coverage, reimbursement, or incentive programs" within Medicare. Furthermore, it goes beyond section 1320e-1(e)'s restriction on the use of QALYs in PCORI and Medicare, because it prohibits all priority-setting methods for life-extending treatments that give lower priority to people with disabilities, rather than merely prohibiting their use as a threshold. ${ }^{94}$

Therefore, even if integrating QALYs into a multi-factor system for setting priorities could permit their use within PCORI, as Bagley argued, section 1320e1(c)(1) would still prohibit their use within Medicare. So long as any aspect of a priority-setting approach gives lower priority to providing a year to someone with a disability than providing a year to someone not disabled, that approach violates section $1320 \mathrm{e}-1(\mathrm{c})(1)$.

However, section $1320 \mathrm{e}-1(\mathrm{c})(1)$ does not entirely prohibit cost-effectiveness or comparative effectiveness research from considering whether someone is disabled. In particular, the statute permits consideration of the alternative to QALYs I discuss above and develop further in Part III-an approach that focuses on future life years and ignores quality of life. The permission to consider future length of life comes from section $1320 \mathrm{e}-1(\mathrm{c})(2)(\mathrm{A})$, which notes that section $1320 \mathrm{e}-1(\mathrm{c})(1)$

shall not be construed to-(i) limit the application of differential copayments under subchapter XVIII of this chapter [i.e., Medicare] based on factors such as cost or type of service; or (ii) prevent the Secretary from using evidence or findings from such comparative clinical effectiveness research in determining coverage, reimbursement, or incentive programs under such subchapter based upon a comparison of the difference in the effectiveness of alternative health care treatments in extending an individual's life due to that individual's age, disability, or terminal illness. ${ }^{96}$

This language indicates that Medicare coverage, reimbursement, and incentive programs can consider the effect of disabilities on a treatment's effectiveness at extending life. For instance, they can consider the fact that Bill's metastatic prostate cancer limits the effectiveness of any healthcare treatment in extending his life when deciding what priority for treatment he, and others with his condition, should receive.

The language of the statute, however, is ambiguous about what constitutes a difference in effectiveness at extending life. One interpretation, which I will call the "length-sensitive" interpretation of comparative effectiveness, would permit Medicare to consider the effect of disability on how much additional life a treatment can be expected to provide. For instance, if a chemotherapeutic drug has an equal chance of extending Bill's and Alice's lives, but could extend Alice's life for more years because her condition is less advanced, this interpretation would permit Medicare to treat Bill
${ }^{93} \mathrm{Id}$.
${ }^{94} \mathrm{Id}$.
${ }^{95} \mathrm{Id}$.
${ }^{96} 42$ U.S.C. $\$ 1320 \mathrm{e}-1(\mathrm{~d})(2)(\mathrm{A})$. 
and Alice differently in terms of cost and reimbursement. Another interpretation, the "length-insensitive" interpretation, would only permit Medicare to consider the effect of disability on whether a treatment can effectively extend life. On this interpretation, Medicare could not favor Alice over Bill in the above situation, since each has the same chance of having his or her life extended by the treatment, even though the number of additional years the treatment provides is longer for Alice. Nothing in the statute compels us to choose the length-insensitive interpretation.

\section{The Elderly}

Section $1320 \mathrm{e}-1(\mathrm{c})(1)$ prohibits Medicare from considering additional years of life for an elderly person as less valuable than additional years of life for a younger person. ${ }^{97}$ This serves to prohibit the use of what medical ethicists have called "ageweighted" theories of priority setting. ${ }^{98}$ In its simplest form, age weighting gives higher priority to extending the life of a younger person than it does to extending the life of an older person by the same amount. ${ }^{99}$ As an example, age weighting would support treating Bill rather than Alice on the basis that Bill has enjoyed fewer years of life than Alice has, but such an approach would be ruled out by the statute's language.

Prominent medical ethicists have defended age weighting on a variety of grounds. Some of their arguments appeal to fairness. Robert Veatch and Alan Williams have argued that giving a younger person priority over an older person for an extra year of life is consistent with a more general principle of giving priority to those who have the least of a good when distributing that good. ${ }^{100}$ That Alice has enjoyed eight cookies while Bill has had only six, for instance, would support giving Bill the next cookie out of the jar. Similarly, that Bill has had only six decades of life while Alice has had eight may support giving Bill priority for additional life. The legal scholar Eric Rakowski has similarly argued that giving priority to younger people is consistent with a principle of equality, since doing so best equalizes people's lifespans. ${ }^{101}$ And Norman Daniels has offered an influential argument for age weighting based on prudence when planning one's life. ${ }^{102}$ While Daniels supports a distribution similar to that proposed by Veatch and Rakowski, he does so for different reasons. Daniels reasons that since we all hope to live through different stages of life, we rationally should prioritize extending our lives earlier on, so that we live to be older, over extending our lives later on. $^{103}$

Other arguments for age weighting appeal to efficiency. Daniels's colleague Frances Kamm has speculated that years of life-like money, housing, and other goods-may have diminishing marginal utility: each additional year of life that a

${ }^{97} 42$ U.S.C. $\$ 1320 \mathrm{e}-1(\mathrm{c})(1)$

${ }^{98}$ Aki Tsuchiya, Age-Related Preferences and Age Weighting Health Benefits, 48 SOC. SCI. \& MED. 267, 268-69 (1999).

${ }^{99}$ Greg Bognar, Age-Weighting, 24 ECON. \& PHIL. 167, 169 (2008); Tsuchiya, supra note 101, at 98 Age-weighting can be combined with QALY approaches, but I focus here on age weighting applied to life year methods that do not consider QALYs.

${ }^{100}$ Robert M. Veatch, How Age Should Matter: Justice as the Basis for Limiting Care to the Elderly, in FACING LIMITS: ETHICS AND HEALTH CARE FOR THE ELDERLy 211, 222-23 (Gerald R. Winslow \& James W. Walters eds., 1993); see also Alan Williams, Intergenerational Equity: An Exploration of the 'Fair Innings' Argument, 6 HEALTH ECON. 117, 117-18, 121 (1997).

${ }^{101}$ Eric Rakowski, Should Health Care Be Rationed by Age?, in CONTROVERSIAL Issues IN AGING 103, 104-06 (Andrew E. Scharlach \& Lenard W. Kaye eds., 1997).

${ }^{102}$ NORMAn DANIELS, AM I MY PARENTS' KeEPER?: AN ESSAY ON JUSTICE BETwEEN THE YOUNG AND THE OLD, at vii, 45-46 (1988).

${ }^{103} \mathrm{Id}$. at 53 . 
person gains has less value than the preceding year. ${ }^{104}$ Therefore, giving priority to younger people produces greater benefits. ${ }^{105}$ Some have defended more complex forms of age weighting, which give different weights to different stages of life rather than constantly decreasing the importance of additional life as a person grows older. Ronald Dworkin argues that we should prioritize adolescents over both younger children and older people, ${ }^{106}$ while Daniel Callahan has argued that we should simply set a threshold over which we assign no value to life extension ${ }^{107}$ Meanwhile, the World Health Organization's disability-adjusted life year approach has adopted age weighting on the basis that an extra year for a person in the middle of their life-a person who is more likely to be involved in caregiving or economic activity - provides more benefits to others than an extra year of life for an older person would. ${ }^{108}$ In a recent law review article, Sean Hannon Williams notes:

Originally, the fair innings argument split people into two groups: those who had surpassed the average life expectancy, and those who had not. The fair innings argument is compatible with a number of different groupings. For example, people might deserve a chance to accomplish certain major life milestones, each of which could be a relevant threshold for purposes of a fair innings argument. Different people might use different milestones, but there is likely to be widespread agreement that children deserve a chance to develop into adults, or perhaps to have children of their own. ${ }^{109}$

Williams's conjecture about "widespread agreement" is supported by surveys of the public, which frequently find some endorsement of age weighting. ${ }^{110}$

Given the multiplicity of age-weighted approaches, section 1320e-1(c)(1)'s prohibition on age weighting has clear significance. However, considering the provision's context substantially complicates its effects: section $1320 \mathrm{e}-1(\mathrm{c})(1)$ explicitly applies only to what the government can do within Medicare, which covers primarily patients sixty-five years of age and over. ${ }^{111}$ As such, section $1320 \mathrm{e}-1(\mathrm{c})(1)$ would not substantially interfere with Callahan's proposal, which treats benefits to people who have lived a "natural life span" the same as middle-aged or young people, but gives them a lower priority than benefits to middle-aged or young people. ${ }^{112}$ Most benefits to middle-aged and young people are not provided via Medicare; the only (1993)

${ }^{104}$ F.M. Kamm, Morality, Mortality Volume I: Death and Whom to Save from It 237-38

${ }^{105} I d$. at 238 .

106 RONALD DWORKIN, LifE's DOMINION: AN ARGUMENT ABOUT ABORTION, EUTHANASIA, AND INDIVIDUAL FREEDOM 87 (1993)

${ }^{107}$ Daniel Callahan, SeTting Limits: Medical Goals in an Aging Society 137-38 (1995).

${ }^{108}$ Sudhir Anand \& Kara Hanson, Disability-Adjusted Life Years: A Critical Review, 16 J. HealTH ECON. 685, 691-92 (1997); C.J.L. Murray, Quantifying the Burden of Disease: The Technical Basis for Disability-Adjusted Life Years, 72 BulL. WORLD HEALTH ORG. 429, 435 (1994), available at http:/www.ncbi.nlm.nih.gov/pmc/articles/PMC2486718/pdf/bullwho00414-0105.pdf.

${ }^{109}$ Sean Hannon Williams, Statistical Children, 30 YALE J. ON REG. 63, 103 (2013); id. at 123 ("People care about the fact that children have more years ahead of them, but this is not necessarily all that people care about. For example, they may care that children have not had their fair innings yet. QALYs do not account for fair innings arguments, and thus it is reasonable to suspect that the social value of protecting children vs. adults will be higher than indicated just by their relative remaining QALYs. This suggests that some form of age-weighting could better align CEA with societal values regarding childhood risk reductions." (citations omitted)). See Williams, supra note 100, for further information on the "fair innings argument."

${ }^{110}$ See sources cited infra note 260

${ }^{111} 42$ U.S.C. $\S 1320 \mathrm{e}-1$ (c)(1) (2012).

${ }^{112}$ See CALLAHAN, supra note 107, at 80-81, 118. 
individuals below sixty-five covered by Medicare are some disabled individuals and individuals with end-stage renal disease. ${ }^{113}$

In contrast, a prohibition on age weighting within PCORI, essential health benefits, or the Exchanges would have swept much more broadly, but such a provision was not enacted. Indeed, application of the expressio unius canon of statutory interpretation would suggest that the ACA's choice to prohibit age weighting only within Medicare permits age weighting elsewhere in the institutions governed by the ACA.

\section{The Terminally Ill}

The most puzzling part of section 1320e-1(c)(1) is its choice to prohibit Medicare from prioritizing life-extending treatments for healthier individuals over life-extending treatments for terminally ill individuals. ${ }^{114}$ When considered alongside section $1320 \mathrm{e}-$ 1(c)(2)(A), which permits the Secretary to consider the effect of terminal illness on the "effectiveness of alternative health care treatments in extending an individual's life," it is not clear what exactly this prohibition entails.

If we use the length-sensitive interpretation of effectiveness, discussed above, this prohibition simply prohibits weightings that count additional years of life for a terminally ill person as less valuable than the same number of additional years of life for someone not terminally ill. So it would require that the two years Bill receives from his treatment be given the same weight as the first two years that Alice receives from hers. But it would not prohibit priority-setting approaches that consider the fact that Alice, because her cancer is not metastatic, can get more additional years of life from treatment than Bill can.

In contrast, if we adopt the length-insensitive interpretation, this prohibition requires that priority setting ignore the fact that Bill stands to gain fewer life years from treatment, and consider only the chance that the treatment will extend his life. Under this interpretation, considering length of life is just as objectionable as considering quality of life. Just as section 1320e-1(c)(1)'s prohibition on disadvantaging people with disabilities recognizes Caroline's future life (despite its quality limitations) as just as worthy of preservation as anyone else's, the lengthinsensitive interpretation of section 1320e-1(c)(1) sees Bill's future life (despite its limited length) as just as worthy of preservation as anyone else's.

Although the length-insensitive interpretation may seem extreme, it has been endorsed in the literature, most prominently by the medical ethicist John Harris. Harris argues that since each person subjectively values her own future life as paramount, regardless of its length, we should not give priority to someone whose life will be extended for a long time by treatment over someone who can live, even if treated, for at most a short period. ${ }^{116}$ In Harris' words:

[T] he anti-ageist argument denies the relevance of age or life expectancy as a criterion absolutely. It argues that even if I know for certain that I have only a little space to live, that space, however short, may be very precious to me. Precious, precisely because it is all the time I have left,

11342 U.S.C. $\$ 1395 \mathrm{c}$ (restricting access to Medicare to individuals over sixty-five, disabled individuals receiving Social Security benefits, and individuals with end-stage renal disease); see also 42 U.S.C. $\$ 13950$ (requiring that Medicare Part B beneficiaries be over sixty-five years of age or eligible for Part A).

${ }^{114} 42$ U.S.C. $\$ 1320 \mathrm{e}-1(\mathrm{c})(1)$.

${ }^{115} 42$ U.S.C. $\$ 1320 \mathrm{e}-1(\mathrm{c})(2)(\mathrm{A})$.

${ }^{116}$ John Harris, Does Justice Require That We Be Ageist?, 8 BIOETHICS 74, 74-83 (1994) 
and just as precious to me on that account as all the time you have left is precious to you, however much those two lifespans differ in length. So that where we both want, equally strongly, to go on living, then we each suffer the same injustice when our lives are cut short or are cut further short. ${ }^{117}$

Harris makes an impassioned case for length insensitivity, but accepting his claims would have striking and counterintuitive implications. Priority-setting methods that adopt Harris's view would require us to be indifferent between extending someone's life for five minutes and extending someone else's for fifty years. ${ }^{118}$

Ignoring differences in the amount of life different patients gain is ethically dubious in at least two ways. First, it requires a particularly strong version of the claim that interpersonal comparisons of well-being are impossible. Even if some interpersonal comparisons are challenging, certain particularly clear ones seem soluble; it seems reasonable to believe that the Romans lost more when Rome burned than Nero gained as he fiddled. ${ }^{119}$ The same seems true when we compare five minutes of life to fifty years. Second, even if someone really could experience just as great a gain of subjective well-being by gaining five extra minutes as someone else could by gaining fifty years, fairness-to the extent it diverges from the maximization of subjective well-being-may still require giving priority to the person who would gain fifty years. Even if a wealthy but miserly person would gain just as much subjective well-being from gaining five dollars as a poor person would gain by doubling her meager income, fairness arguably still requires us to help the poor person first. ${ }^{120}$

As such, section $1320 \mathrm{e}-1(\mathrm{c})(2)(\mathrm{A})$ is better interpreted in a length-sensitive way. The most natural way of understanding the language permitting Medicare to consider a "difference in extending life" 21 would include not only differences in whether a treatment extends someone's life, but by how many years that life is extended. The length-sensitive interpretation, although it considers differences between patients when determining the potential effectiveness of treatments, regards an additional year of life for any patient as equally important. Individuals with short life expectancies, unlike the elderly or the disabled, are not a group elsewhere recognized in antidiscrimination law.

One potential hybrid between the length sensitive and length insensitive views would focus on the language in section 1320e-1(c)(2)(A) that permits "comparison of the difference in the effectiveness of alternative health care treatments in extending an individual's life due to that individual's age, disability, or terminal illness," and read the "due to" language to permit consideration of patients' different future lengths of life when that difference in length of life stems from an interaction between the patient's illness and the treatment. ${ }^{122}$ Per this hybrid view, Medicare could consider the

117 JOHN HARRIS, THE VALUE OF LIFE: AN INTRODUCTION TO MEDICAL ETHICS 90 (Taylor \& Francis e-Library ed., 2001) (footnotes omitted).

${ }^{118}$ David Orentlicher has defended a similar but less extreme view of length insensitivity, asking us to treat as equal all gains in lifespan that are not de minimis. David Orentlicher, Destructuring Disability: Rationing of Health Care and Unfair Discrimination Against the Sick, 31 HARV. C.R. -C.L. L. REV. 49, $72-$ 73 (1996) ("[]]f an organ transplant program excluded persons whose coexisting illnesses prevented them from gaining more than a few months of benefit from an organ, there should be no problem with the exclusion. If, however, a program excluded persons who would gain a few years of benefit on the ground that other persons would gain even more, that kind of exclusion should not be permitted.").

${ }^{119}$ AMARTYA SEN, RATIONALITY AND FREEDOM 79 (2004).

${ }^{120}$ Cf. John Broome, The Ethics of Climate Change, 298 SCI. AM. 96, 99-100 (2008) (differentiating fairness-based, "prioritarian" arguments from diminishing marginal utility arguments).

${ }^{121} 42$ U.S.C. $\$ 1320 \mathrm{e}-1(\mathrm{c})(2)(\mathrm{A})(2012)$.

${ }^{122} \mathrm{Id}$. 
fact that Bill's metastatic prostate cancer limits the amount of additional life that chemotherapy for that cancer can provide, but could not consider his cancer when evaluating the benefits of saving Bill from an unrelated illness, such as heart failure. Although this hybrid view is more plausible than the length-insensitive view, it construes "due to" overly narrowly. That Bill's metastatic cancer limits how effective heart disease treatments can be at extending his life by posing a second, independent threat to his life, rather than by interfering directly with treatment, does not prevent the cancer from counting as a limitation on heart disease treatment. Additionally, it is challenging to imagine how comparative effectiveness research could identify these sorts of fine distinctions in causal structure.

The strongest argument for the length-insensitive interpretation of section $1320 \mathrm{e}-$ 1(c)(2)(A) appeals to concerns about surplusage: permitting Medicare to consider the effects of terminal illness on a treatment's effectiveness in lengthening someone's life might appear to provide no special protection at all to people with terminal illnesses. However, it still prohibits one recognized form of priority setting that would disadvantage people with terminal illnesses, which is the use of thresholds that treat small amounts of life as irrelevant. ${ }^{123}$

Even though the length-sensitive interpretation of section $1320 \mathrm{e}-1(\mathrm{c})(2)(\mathrm{A})$ permits Medicare to give lower priority to treatments for the terminally ill on the basis that treatment will add fewer years to their lives, it does not permit treating the future life of a terminally ill individual - no matter how short - as any less important than the same amount of future life for some other individual. Even though we can prioritize helping Caroline live for six more years over helping Bill live for six more months, section $1320 \mathrm{e}-1$ (c)(1) prohibits priority setting that would favor helping a healthy person live for six more months over helping a terminally ill person live six more months. ${ }^{124}$

\section{Essential Health BenEFits}

The next section of the ACA I discuss applies to any health plan offered through an Exchange within the ACA. This section sets standards for the "essential health benefits" that any plan offered through an Exchange must provide.

\section{Nondiscrimination in Design}

The ACA requires that, in defining a list of essential health benefits, the Secretary of the Department of Health and Human Services (HHS) "not make coverage decisions, determine reimbursement rates, establish incentive programs, or design benefits in ways that discriminate against individuals because of their age, disability, or expected length of life." ${ }^{25}$ The requirement not to discriminate against individuals because of disability seems to parallel the restrictions placed on PCORI and Medicare, while the restriction on age discrimination seems parallel to the restrictions placed on Medicare.

However, the language here is less specific than the language of the Medicare and PCORI restrictions. While the Medicare restrictions specifically prohibit treating the extension of life for older, disabled, or terminally ill people as less important, ${ }^{126}$ and the PCORI restrictions limit the use of QALYs because they disadvantage people with

\footnotetext{
${ }^{123}$ Cf. Bognar, supra note 99 , at $172-73$ (discussing examples).

${ }^{124} 42$ U.S.C. $\$ 1320 \mathrm{e}-1(\mathrm{c})(1)$.

${ }^{125}$ Id. $\S 18022$ (b)(4)(B).

${ }^{126}$ Id. $\S 1320 \mathrm{e}-1(\mathrm{c})(1)$
} 
disabilities, ${ }^{127}$ the essential health benefit provisions refer to the more general concept of discrimination. ${ }^{128}$ Depending on how we understand this concept, it may seriously limit the use of comparative effectiveness research in defining essential health benefits.

One interpretation of "discriminate against," which I'll call the "no-weighting" interpretation, defines discrimination against someone as treating a benefit to her differently, because of her disability, age, or expected length of life. This interpretation would treat section 18022(b)(4)(B) as parallel to section 1320e-1, which prohibits counting an extra year of life for Bill as less valuable because he is disabled, but does not prohibit counting five years of life for Alice as more valuable than two years of life for Bill, even when the reason that Bill cannot benefit more is his disability. ${ }^{129}$ It would also allow us to consider the fact that some treatments may cause disability when deciding what priority to give those treatments.

In contrast, the "benefit-insensitive" interpretation would define discrimination to include all cases where someone receives a lower priority for a benefit because of her disability, age, or expected length of life-even where the lower priority stems from the fact that her disability, age, or expected length of life affects her prospect of benefit or its expected magnitude.

Many discussions of this language, as well as the related language in the Code of Federal Regulations, seem - at least on the surface - to embrace the benefit-insensitive interpretation. For instance, the National Patient Advocate Foundation (NPAF) argues that

[o]ne's expected length of life is precisely that-expected. The length of one's life is not certain and essential health benefit decisions should not make certain that which is merely expected by limiting care because of its cost. Rather, the decision regarding health benefit availability for those patients who are not expected to live very long should be left up to patients, their families and caregivers. ${ }^{130}$

NPAF's view clearly rejects any priority setting for essential health benefits that gives a lower priority to treatments that are not expected to produce many years of life because their recipients have a very limited life expectancy. ${ }^{131}$ In NPAF's view, health insurers must ignore the expected medical benefit of interventions when deciding which interventions to treat as essential. ${ }^{132}$

Other advocates for expanded access, however, have not advanced such a sweeping interpretation. For instance, the Orthotic and Prosthetic Alliance argued that section $18022(\mathrm{~b})(4)(\mathrm{B})$ requires that

as long as a patient is motivated to ambulate and capable of doing so, prosthetic care is appropriate and the patient's age, disability status, or expected length of their life cannot be used by health plans to deny

${ }^{127} I d$.

${ }^{128}$ Id. $\S 18022(\mathrm{~b})(4)$.

${ }^{129}$ Id. $\$ \$ 1320 \mathrm{e}-1,18022(\mathrm{~b})(4)(\mathrm{B})$.

${ }^{130}$ Rene Cabral-Daniels, Exec. Vice President of Regulatory Affairs, Nat'l Patient Advocate Fund, Comments at the Department of Health and Human Services' Open Comment Session for Consumer Advocates on Essential Health Benefits (Oct. 20, 2011), available at http://www.npaf.org/ files/NPAF $\% 20$ Comments $\% 20$ Provided $\% 20$ to $\% 20 \mathrm{HHS} \% 20$ on $\% 20$ Essential $\% 20 \mathrm{Health} \% 20$ Benefits $\% 20 \mathrm{Oc}$ t\%2020\%202011.pdf.

${ }^{131}$ Id. 
coverage for O\&P [orthotic and prosthetic] care . . . ${ }^{133}$

Section 18022(b)(4)(B) only applies to essential benefits; age, disability, and other factors may be appropriate when setting priorities for nonessential benefits. ${ }^{134}$ But, more importantly, the Orthotic and Prosthetic Alliance's interpretation of section 18022 (b)(4)(B) requires the provision of prosthetic care only "as long as a patient is motivated to ambulate and capable of doing so." ${ }^{.135}$ They would not prohibit a plan from refusing to provide a prosthetic to someone who will never walk again even if she receives the prosthetic, because some other disability prevents her doing so or because she is certain to die before she recovers enough to walk. ${ }^{136}$ In so doing, they adopt not the benefit-insensitive view, but some sort of threshold view that patients who can gain sufficient benefit from an intervention (where their capacity to benefit may depend on their age, disability, or expected length of life), should be entitled to the intervention, even though their age, disability, or expected length of life limits the extent of the benefit they can receive. ${ }^{137}$

Other contexts in law seem to adopt the no-weighting view, rather than the benefit-insensitive view. The tort system, for instance, permits judges and juries to consider the effect of a plaintiff's age, disability, and expected length of life on her future earning power when calculating the damages she receives, although it does not permit directly discounting future wages based on the fact that a plaintiff is disabled. ${ }^{138}$

Another interpretation of discrimination regards discrimination on the basis of age, disability, or expected length of life as the arbitrary use of these factors. We might think of this interpretation as mandating a sort of "rational basis test" for priority-setting decisions that consider age, disability, or expected length of life. Sara Rosenbaum argues that, rather than prohibiting the use of age, disability, and expected length of life in setting priorities,

[t] he statute bars discrimination, but not the use of patient characteristics when such characteristics rest on a reasonable clinical and scientific evidentiary base. A decision cannot be made "on the basis of age," but a decision based on clinical factors (age is a recognized clinical factor when, for example, age is used to determine when to immunize a child against certain diseases) would not be a decision based on age. ${ }^{139}$

HHS appears to have adopted Rosenbaum's suggestion in its own interpretation of the ACA. ${ }^{140}$ HHS noted that "[m]any commenters expressed concern that [the antidiscrimination provisions] would prevent issuers from employing traditional medical management techniques, with some requesting that we revise regulatory text to indicate that evidence-based techniques would not be considered discriminatory. Others expressed ongoing concern that medical management techniques were often

${ }^{133}$ Orthotic \& Prosthetic Alliance, supra note 41.

${ }_{134}^{134} 42$ U.S.C. $\S 18022(\mathrm{~b})(4)(B)$.

${ }^{135}$ Orthotic \& Prosthetic Alliance, supra note 41.

${ }^{136}$ See id.

${ }^{137}$ Cf. Orentlicher, supra note 118 , at $72-73$.

${ }^{138}$ E.g., Loftin v. Wilson, 67 So. 2d 185, 188 (Fla. 1953) (holding that, when assessing damages, "the jury must consider the person's health, habits, occupation, surroundings and any other elements, which in his case will be likely to operate for or against his expected length of life, as well as the fact that his earning power may diminish as his physical and mental strength decline").

${ }^{139}$ Inst. of Medicine, Perspectives on Essential Health Benefits: Workshop Report 87 (2012).

${ }^{140}$ Patient Protection and Affordable Care Act; Standards Related to Essential Health Benefits, Actuarial Value, and Accreditation, 78 Fed. Reg. 12,834, 12,847 (Feb. 25, 2013) (to be codified at 45 C.F.R. pts. 147, 155, 156). 
used as nuanced mechanisms for discrimination."141 HHS's response to these commenters is that an insurance plan cannot act "in a manner that discriminates on the basis of membership in a particular group based on factors such as age, disability, or expected length of life that are not based on nationally recognized, clinically appropriate standards of medical practice evidence or not medically indicated and evidence-based." 142 HHS then gives the example that "a reasonable medical management technique would be to require preauthorization for coverage of the zoster (shingles) vaccine in persons under 60 years of age, consistent with the recommendation of the Advisory Committee on Immunization Practices," and concludes that "nothing in this section shall be construed to prevent an issuer from using reasonable medical management techniques." 143 South Dakota has adopted similar statutory language, specifying that "[i]ssuers may continue to use reasonable medical management techniques that are evidence based."144

HHS's and Rosenbaum's attempts to define discrimination as conduct that falls outside of recognized medical practice are tempting: they delegate to the medical and scientific professions the task of defining when considerations of age, disability, and expected length of life are appropriate in healthcare. However, these definitional decisions are not technical ones. Rather, they are value judgments, which physicians have no special expertise in making. ${ }^{145}$ For instance, physicians may decide-and indeed have decided - that certain transplants are not indicated for patients over a certain age. But physicians' custom does not necessarily make their choices about medical priorities just. ${ }^{146}$ Furthermore, defining discrimination as noncompliance with custom makes it hard to see how new customs could evolve.

Finally, since the essential health benefits requirements are regulations on private plans offered through the Exchanges, it is worth considering a different interpretation of section 18022(b)(4)(B): that the language is actually intended to target efforts by insurers to exclude people they expect to have long lives. ${ }^{147} 45 \mathrm{CFR} \S 147.104$ provides:

A health insurance issuer and its officials, employees, agents and representatives . . cannot employ marketing practices or benefit designs that will have the effect of discouraging the enrollment of individuals with significant health needs in health insurance coverage or discriminate based on an individual's race, color, national origin, present or predicted disability, age, sex, gender identity, sexual orientation, expected length of life, degree of medical dependency, quality of life, or other health conditions. ${ }^{148}$

${ }^{141} I d$.

${ }^{142} I d$. (emphasis added).

${ }^{143} \mathrm{Id}$.

${ }^{144}$ S.D. ADMIN. R. 20:06:56:09 (2013)

${ }^{145}$ See Tony Hope et al., "Not Clinically Indicated": Patients' Interests or Resource Allocation?, 306 BRIT. MED. J. 379, 380 (1993); cf. E. Haavi Morreim, Futilitarianism, Exoticare, and Coerced Altruism: The ADA Meets Its Limits, 25 SETON HALL L. REv. 883, 907 (1995) ("[P]hysicians cannot appeal to medical science to determine that a patient's life - his very existence - is somehow 'medically contraindicated.' It is here that controversies should be resolved, not by professional declaration, but by societal negotiation.").

${ }^{146} \mathrm{Cf}$. Benjamin Eidelson, Comment, Kidney Allocation and the Limits of the Age Discrimination Act, 122 Y ALE L.J. 1635, 1645 (2013) ("But when age is cast as a proxy for conditions such as heart disease, and incorporated alongside other paradigmatically medical criteria such as diabetes status, the inference from years lived to years left is attenuated and 'medicalized' in a way that may invite greater deference.").

${ }^{147}$ See Thomas L. Greaney, The Affordable Care Act and Competition Policy: Antidote or Placebo?, 89 OR. L. REV. 811,827 (2011).

${ }^{148} 45$ C.F.R. $\$ 147.104$ (e) (2013). 
The placement of this language suggests that it aims to prohibit insurers from cherrypicking healthy patients or violating other provisions of antidiscrimination law ${ }^{149}$ not that it aims to prohibit insurers from considering the fact that a treatment may result in disability or may fail to extend life as much as an alternative.

\section{Nondiscrimination in Provision}

The section on essential health benefits also contains language that prevents the denial of benefits classified as essential to individuals based on certain factors. ${ }^{150}$ It requires that the Secretary:

ensure that health benefits established as essential not be subject to denial to individuals against their wishes on the basis of the individuals' age or expected length of life or of the individuals' present or predicted disability, degree of medical dependency, or quality of life. ${ }^{151}$

Similar language also exists in a section on Medicare Advantage demonstration projects, which provides that:

The criteria employed under the demonstration program under this section to evaluate outcomes and determine best practice guidelines and incentives shall not be used as a basis for the denial of medicare benefits under the demonstration program to patients against their wishes (or if the patient is incompetent, against the wishes of the patient's surrogate) on the basis of the patient's age or expected length of life or of the patient's present or predicted disability, degree of medical dependency, or quality of life. ${ }^{152}$

Section 18022(b)(4)(D) pertains to the provision of benefits antecedently "established as essential," and thus operates in conjunction with section 18022(b)(4)(B), which proscribes discrimination in the determination of which benefits are essential. ${ }^{153}$ However, even if section 18022(b)(4)(B)'s prohibition on discrimination is understood expansively, section 18022(b)(4)(D) will still be relevant. A health benefit defined as essential using nondiscriminatory criteria might still in practice be denied to individuals in a way that violates section 18022(b)(4)(D). And the Medicare Advantage provisions are particularly significant, since Medicare is not otherwise prohibited from considering the effect of age, disability, or terminal illness on treatment effectiveness. ${ }^{154}$

Section 18022(b)(4)(D) and similar statutes may require the provision, at a patient's request, of treatments even in cases where the treatment provides minimal benefit or could be harmful to the patient. For instance, it might interfere with Oregon's Medicaid program's efforts to restrict access to cancer treatment "with an

${ }^{149}$ See Greaney, supra note 147 , at 827.

${ }^{150} 42$ U.S.C. $\$ 18022$ (b)(4)(D) (2012).

${ }^{151}$ Id.

${ }^{152} 42$ U.S.C. $\$ 1395 \mathrm{cc}-3$

${ }^{153} I d . \S 18022(\mathrm{~b})(4)(\mathrm{B})$.

${ }^{154}$ See, e.g., Michael J. DeBoer, Medicare Coverage Policy and Decision Making, Preventive Services, and Comparative Effectiveness Research Before and After the Affordable Care Act, 7 J. HEALTH \& BIOMEDICAL L. 493, 563 (2012) (quoting 42 U.S.C. $\$ 1320 \mathrm{e}-1$ (c)(1) (2012)) ("The ACA does, however, prohibit the Secretary from using evidence or findings from comparative clinical effectiveness research under section 1181 of the Social Security Act in determining Medicare coverage, reimbursement, or incentive programs 'in a manner that treats extending the life of an elderly, disabled, or terminally ill individual as of lower value than extending the life of an individual who is younger, nondisabled, or not terminally ill.""). 
intent to prolong survival" on the basis of quality of life:

Treatment with intent to prolong survival is not a covered service for patients who have progressive metastatic cancer with

1) severe co-morbidities unrelated to the cancer that result in significant impairment in two or more major organ systems which would affect efficacy and/or toxicity of therapy; OR

2) a continued decline in spite of best available therapy with a non reversible Karnofsky Performance Status or Palliative Performance score of $<50 \%$ with ECOG performance status of 3 or higher which are not due to a pre-existing disability. ${ }^{155}$

This Oregon language has been challenged by a coalition of cancer advocacy groups, who allege that it constitutes a violation of section $18022(\mathrm{~b})(4)(\mathrm{D}){ }^{156}$ However, although section $18022(b)(4)(D)$ is broader than section $18022(b)(4)(B)$, since it prohibits decisions "on the basis of" certain factors rather than merely prohibiting discrimination on the basis of those factors, ${ }^{157}$ Oregon might argue that its policy is justified on the basis of medical inappropriateness, or on the basis of a physician's duty not to harm, rather than on the basis of bare life expectancy.

To settle the dispute, agencies and courts would have to offer their own interpretations of the "on the basis of" language. The construction of similar text in other statutes, such as the Age Discrimination in Employment Act, the Age Discrimination Act, and the Americans with Disabilities Act, has been much debated. ${ }^{158}$ Some cases have suggested that "on the basis of" requires proof of proximate causation, ${ }^{159}$ while others note that consideration of age may be appropriate where consideration of other factors is categorically prohibited ${ }^{160}$ There is also active debate over whether subtle differences in language between statutes affect the applicability of case law interpreting similar statutes. ${ }^{181}$

155 Health Evidence Review Commission: New Cancer Treatment Guideline, OREgon.gov, http://www.oregon.gov/oha/herc/Pages/New-Cancer-Treatment-Guideline.aspx (last visited Apr. 2, 2015).

${ }^{156}$ See, e.g., Letter from The Leukemia \& Lymphoma Soc'y et al., to Diane Gerrits, Dir. of the Div. of State Demonstrations \& Waivers, Ctrs. for Medicare \& Medicaid Servs. (Sept. 27, 2013) (on file with author), available at

http://community.lls.org/blog/1/entry-282-oregon-cms-advocate-letter/.

${ }^{157}$ Compare 42 U.S.C. $\$ 18022$ (b)(4)(D) (2012), with $\$ 18022$ (b)(4)(B).

${ }^{158}$ See Univ. of Tex. Sw. Med. Ctr. v. Nassar, 133 S. Ct. 2517, 2531 (2013) (discussing the Supreme Court's disparate interpretations of "discrimination" in the context of the Americans with Disabilities Act and the Age Discrimination in Employment Act); Gross v. FBL Fin. Servs., 557 U.S. 167, 176 (2009) (analyzing the plain meaning of the phrase "because of" in the Age Discrimination in Employment Act); see also Ky. Ret. Sys. v. EEOC, 554 U.S. 135, 142 (2008) (considering legislative intent when ruling on a disparate-treatment claim under the Age Discrimination in Employment Act); Hazen Paper Co. v. Biggins, 507 U.S. 604, 608 (1993) ("The Courts of Appeals repeatedly have faced the question whether an employer violates the ADEA by acting on the basis of a factor, such as an employee's pension status or seniority, that is empirically correlated with age.").

${ }^{159}$ E.g., Petock v. Thomas Jefferson Univ., 630 F. Supp. 187, 189 (E.D. Pa. 1986) (citing Lewis v. Univ. of Pittsburgh, 725 F.2d 910, 914 (3d Cir. 1983)).

${ }^{160}$ Smith v. City of Jackson, 544 U.S. 228, 240 (2005) ("[A]ge, unlike race or other classifications protected by Title VII, not uncommonly has relevance to an individual's capacity to engage in certain types of employment.").

${ }^{161}$ See Serwatka v. Rockwell Automation, Inc., 591 F.3d 957, 961 n. 1 (7th Cir. 2010) (explaining that older "because of" language in Americans with Disabilities Act entailed a but-for causation requirement, but noting that newer "on the basis of" language might have different implications); Quillen v. Touchstone Med. Imaging L.L.C., 15 F. Supp. 3d 774, 780 n.10 (M.D. Tenn. Apr. 18, 2014) (collecting cases interpreting the "on the basis of" language); Southerland v. Dep't of Def., 2011 M.S.P.B. 92, 38 (2011), aff'd as modified, 119 M.S.P.B. 46 (2013) (holding "that the phrase 'on the basis of' in the [ADA Amendments Act of 2008] means the same thing as 'because of' in the ADA and, therefore, requires application of the same 'but for' 
Minnesota's state statutory language on essential health benefits similarly states that:

"Clinically effective" means that the use of a particular health technology or service improves or prevents a decline in patient clinical status, as measured by medical condition, survival rates, and other variables, and that the use of the particular technology or service demonstrates a clinical or outcome advantage over alternative technologies or services. This definition shall not be used to exclude or deny technology or treatment necessary to preserve life on the basis of an individual's age or expected length of life or of the individual's present or predicted disability, degree of medical dependency, or quality of life. $^{162}$

The definition of "cost-effective" contains an identical proviso. ${ }^{163}$ However, the Minnesota language differs subtly from the ACA's essential health benefits language: rather than applying to all health benefits, the Minnesota statute only prohibits the use of clinical effectiveness or cost-effectiveness data to deny access to treatment where the treatments in question are "necessary to preserve life." 164

Ultimately, assessing how to understand the antidiscrimination requirements on the provision of essential health benefits may depend on the details of the benefits in question. If the benefit is a low cost treatment that minimizes pain and suffering and whose effectiveness does not differ drastically between patients, then it could make sense not to deny a benefit on the basis of differences in medical benefit that stem from age, disability, or short life expectancy. Providing such a benefit, regardless of whether its effectiveness is low because of the patient's comorbidities or advanced age, might have the expressive significance of recognizing the patient's continued membership in the community, and the importance of responding to her preferences about healthcare. ${ }^{165}$ Such considerations might outweigh concerns about low costeffectiveness.

In contrast, if some benefits regarded as essential are high cost, last chance treatments whose benefit is almost nonexistent for some already very ill patients, preventing the consideration of age, disability, or prognosis seems much harder to defend. Requiring the provision of such treatments would require the healthcare system to incur high costs and could place physicians in the position of providing medical care they professionally regard as harmful.

Ultimately, the most challenging cases involve high cost treatments that do prevent pain and suffering. In such cases, a pure cost-effectiveness approach would consider the differing extents to which the treatment prevents pain and suffering in different patients, while an approach that ignores prognosis would treat patients identically. Where the treatment to be provided will not be provided to everyone, treating patients identically has the expressive virtue of equal regard for all, but the disadvantage of ignoring differences in patients' needs and capacity to benefit.

test discussed in Gross"); Brian S. Clarke, Grossly Restricted Pleading: Twombly/Iqbal, Gross, and Cannibalistic Facts in Compound Employment Discrimination Claims, 2010 UTAH L. REV. 1101, 1125 n.164 (2010) (asserting that "the terms "because of" and 'on the basis of" are essentially identical")

${ }^{162}$ MinN. STAT. ANN. § 62U.01 subd. 3 (West 2013).

${ }^{163} I d . \S 62 U .01$ subd. 5 .

${ }^{164} \mathrm{Id}$.

${ }^{165}$ For a discussion of the expressive significance of legal requirements, see generally Elizabeth $\mathrm{S}$. Anderson \& Richard H. Pildes, Expressive Theories of Law: A General Restatement, 148 U. PA. L. REV. $1503(2000)$. 


\section{Fairness to Diverse Segments of the Population}

The essential health benefits section contains language that requires a much broader shift away from thinking in traditional cost-effectiveness terms than any of the other text does. This section specifies that essential health benefit determinations must "take into account the health care needs of diverse segments of the population, including women, children, persons with disabilities, and other groups." ${ }^{366}$ This section would prohibit the selection of essential health benefits simply by beginning with the most cost-effective interventions and proceeding down the list until some cutoff point was reached. ${ }^{167}$ Rather, choices about essential health benefits should be fair to different relevant subgroups within the population. For example, even if the greatest net benefit could be obtained by providing services that reach only urban populations, appropriately considering the needs of subgroups requires deviating from the strict pursuit of total benefit.

Among the most major challenges section 18022(b)(4)(C) poses is the question of which "diverse segments" are relevant. While the statute specifies that women, children, and persons with disabilities must be considered when setting priorities, it leaves open which other categories might be relevant. ${ }^{168}$ In its Final Rule on Essential Health Benefits, codified at 45 C.F.R. $\S 156.125$, HHS stated that an issuer of insurance fails to provide essential health benefits if "its benefit design, or the implementation of its benefit design, discriminates based on an individual's age, expected length of life, present or predicted disability, degree of medical dependency, quality of life, or other health conditions," 169 or discriminates "on the basis of race, color, national origin, disability, age, sex, gender identity or sexual orientation." 170

The most likely provisions to produce debate are those familiar to antidiscrimination law but also clearly relevant to medical practice, such as age and disability, as well as those unfamiliar to antidiscrimination law, such as length and quality of life, and degree of medical dependency. Some of the factors discussed in section 156.125, such as race, color, national origin, gender, gender identity, and sexual orientation, ${ }^{171}$ are somewhat less likely to produce debate. However, given that some vulnerabilities - such as sickle cell trait and prostate cancer-are directly connected to these factors, and many others are correlated with them, these antidiscrimination rules may play a role here as well.

That the Final Rule employs the concept of discrimination based on a factor, rather than categorically stating that certain factors can never be considered, places the question of which forms of priority setting constitute discrimination front and center. ${ }^{172}$ Perhaps the most important threshold questions here will involve the line between "reasonable medical management techniques," which the regulation regards as nondiscriminatory, and discriminatory designs. There has been recent debate, but not yet litigation, regarding what constitutes a reasonable medical management

${ }^{166} 42$ U.S.C. $\$ 18022$ (b)(4)(C) (2012).

${ }^{167} I d$. $\S 18022(\mathrm{~b})(4)(\mathrm{A})$. This was more or less the approach that Oregon followed in initial versions of its Medicaid plan. See La Puma, supra note 67, at 434 ("The legislature has decided how far down the list to

go ... and how much more to approve the health care of Oregon's medically indigent.").

${ }^{168}$ See id. $\$ 18022(\mathrm{~b})(4)(\mathrm{C})$ (using the phrase "other groups").

16945 C.F.R. $\$ 156.125$ (a) (2014).

${ }^{170} \mathrm{Id}$. $\S 156.200$ (e); see also id. $\S 156.125$ (b) ("An issuer providing EHB must comply with the requirements of $\S 156.200(\mathrm{e})$ of this subchapter.")

${ }^{171}$ See id. $\$ \S 156.125(\mathrm{~b}), 156.200(\mathrm{e})$.

172 See generally Jessica L. Roberts, 'Healthism': A Critique of the Antidiscrimination Approach to Health Insurance and Health-Care Reform, 2012 U. ILL. L. REV. 1159, 1187-89 (reviewing and critiquing antidiscrimination provisions in the ACA). 
technique versus a discriminatory design. Sara Rosenbaum notes that:

the rules provide no specific illustrations of what would be discriminatory, nor are illustrative examples provided as to what would be an appropriate and reasonable medical management technique. . . . It is unclear what types of conduct HHS believes would cross the line, nor do the rules indicate the process that will be used to monitor discrimination. The Preamble ... however, clarifies that HHS expects that states, as the primary enforcement arm of [essential health benefit] requirements as an insurance market regulatory standard, will take the lead in enforcing this provision (as well as other provisions of the Act related to market reforms). An unknown issue is how states are approaching the problem of insurance discrimination, how discrimination is defined, or the procedures that will be used to identify discrimination (plan document reviews; actual review of coverage decisions and claims payment). Presumably individuals may appeal coverage denials on the basis of the discrimination prohibition, which offers one mechanism for reviewing plan conduct. ${ }^{173}$

This lack of clarity has prompted worries from providers. ${ }^{174}$ Concerns about whether benefit designs are discriminatory fall into three broad categories. One set of concerns focuses on whether designs treat individual participants differently based on health condition; $^{175}$ another set focuses on whether designs systematically disadvantage individuals (e.g., all individuals with diabetes or all organ transplant candidates) on the basis of their membership in an illness-based class. ${ }^{176} \mathrm{~A}$ third set of questions concerns insurance designs that systematically disadvantage individuals who are members of non-illness-based classes-for instance, women or children. ${ }^{177}$

\section{a. Discrimination Against Ill Individuals}

If 45 C.F.R. $\$ 156.125$ (a) is read to require that individuals not receive differential treatment from insurers based on their health conditions, the regulation's impact on efforts to set priorities and promote cost-effectiveness might be substantial. The National Association of Insurance Commissioners notes that "[ $t$ ]his provision might be interpreted as preempting state laws that permit medical necessity limitations on coverage or promote the cost-effective delivery of benefits, except to the extent that they constitute the kind of 'reasonable medical management techniques' permitted by

\footnotetext{
${ }^{173}$ Sara Rosenbaum, Update: Essential Health Benefits Final Rule, HEALTHREFORMGPS (Mar. 13, 2013), http://healthreformgps.org/resources/update-essential-health-benefits-final-rule-2/.

174 Katie Keith eT AL., Nondiscrimination Under the AFFordable Care ACt 12 (2013), available at http://ssrn.com/abstract=2362942 (reporting that "one insurer questioned whether the use of age-based clinical criteria (such as preventive services recommended only for children or adults of a certain age) would be considered 'reasonable medical management techniques' (which is allowed under federal regulations) or discriminatory based on age (which is prohibited)").

${ }^{175}$ See id. at 7 ("[I]nsurers in most states can deny or limit coverage based on health status.") (citing KAISER FAMILY FOUND., HEALTH INSURANCE MARKET REFORMS: GUARANTEED ISSUE 1 (2012), available at http://kaiserfamilyfoundation.files.wordpress.com/2013/01/8327.pdf).

${ }^{176}$ Id. (citing Dana P. Goldman et al., Benefit Design and Specialty Drug Use, 25 HeALTH AfF. 1319 (2006); KATE FITCH \& BRUCE PyENSON, BENEFIT DESIGNS FOR High CosT MEDICAL CONDITIONS (2011)) ("[C]onsumers may face high cost-sharing for chronic diseases.").

${ }^{177}$ Id. (citing DaniElle GARRETT ET AL., TuRning to FaIRNESS: Insurance Discrimination AGAINST WOMEN TODAY AND THE AFFORDABLE CARE ACT 7 (2012), available at http://www.nwlc.org/ sites/default/files/pdfs/nwlc_2012_turningtofairness_report.pdf) ("Women continue to be charged more for coverage.").
} 
HHS under 45 CFR $\S 156.125$ (c). ${ }^{1178}$ For example, a recent presentation asks whether a variety of benefit designs might constitute discrimination, such as formularies that exclude drugs and devices subject to registries; restrictions of patients on many prescriptions to a single pharmacy provider; value-based designs that eliminate copayments and coinsurance for generic drugs while maintaining them for branded drugs; and "fail first" policies where patients must first try the preferred drug before receiving alternatives. ${ }^{179}$ Many of these designs have the potential to maintain a high overall level of medical care while containing costs, but could disadvantage specific individuals who suffer adverse events from the interventions that are overall most costeffective. For example, formularies may serve the interests of the patient population as a whole while disadvantaging specific patients: a recent commentary alleges that formularies "subordinate the heterogeneity of patient need and response to the primacy of cost control." 180

While policies catering to each individual's unique medical situation might be desirable in an ideal world, some disadvantage to individuals with unusual or costly medical needs seems inevitable and, while disadvantaging, not objectionably discriminatory. Every population-wide rule, from the age of majority to the speed limit, invariably has negative impacts on certain individuals. While systematic disadvantage to a protected class would warrant remedial action, the mere fact that a rule has winners and losers does not. Permitting individuals who lose out under a systematically applied, evidence-based guideline due to their individual medical situation, rather than any membership in a protected class, to prevail on complaints of discrimination would make the application of guidelines impossible and, more importantly, would stretch the meaning of discrimination beyond recognition. While a few individuals have challenged regulations as arbitrary under the Equal Protection Clause (in what are called "class of one" cases) and prevailed, ${ }^{181}$ such claims must involve intentional discrimination-or, in some courts' view, animus-motivated discrimination ${ }^{182}$ - between individuals who are strictly identically situated: the uniqueness of an individual's situation is not enough to support a "class of one" claim. ${ }^{183}$ As the Supreme Court recently noted, antidiscrimination law cannot stipulate

178 ACA Impact on State Regulatory Authority: Qualified Health Plans, NAT'L INST. INS. COMMISSIONERS, http://web.archive.org/web/20130502150248/http://www.naic.org/documents/committees b_exchanges_her_reg_alt_wg_130325_analysis_hix.pdf (last visited Feb. 17, 2015).

${ }^{179}$ DONNA A. BOSWELl, ACCESS TO CARE UNDER HEAlTh REForm: HOW WILl PATIENTS OBTAIN INNOVATIVE THERAPIES 20 (2013), available at http://www.womeningovernment.org/files/ DonnaBoswell.pdf.

${ }^{180}$ Gary Puckrein, The National Healthcare Quality Report and Essential Health Benefits: Opportunity Squandered, HUFFINGTON POST (May 29, 2013), http://www.huffingtonpost.com/gary-puckrein/thenational-healthcare-q b 3352778.html; Letter from the AIDS Action Comm. of Mass. et al., to Kathleen Sebelius, Sec'y, Health \& Human Servs. (Oct. 2, 2012) (on file with the AIDS Institute), available at http://www.theaidsinstitute.org/sites/default/files/attachments/Sebelius\%20EHB\%20letter\%20oct\%202012.p df.

${ }^{181}$ See, e.g., Vill. of Willowbrook v. Olech, 528 U.S. 562, 563 (2000) (holding that an individual's allegation that a regulation's application to her was "irrational and wholly arbitrary" was sufficient to state a claim for relief under the Equal Protection Clause (internal quotation marks omitted))

${ }^{182}$ See Racine Charter One, Inc. v. Racine Unified Sch. Dist., 424 F.3d 677, 683-84 (7th Cir. 2005) (collecting cases); see also Benjamin L. Schuster, Fighting Disparate Treatment: Using the "Class of One" Equal Protection Doctrine in Eminent Domain Settlement Negotiations, 45 REAL PROP. TR. \& EsT. L.J. 369, 392 (2010) (noting that some courts require animus in "class of one" cases).

${ }^{183}$ E.g., Level Dev. Corp. v. Pisani, No. 3:10CV820 (MRK), 2012 WL 2397360, at*4 (D. Conn. June 25,2012 ) ("Instead of pointing to the similarities between Level and its proposed comparators, Level's brief on this issue lingers instead on the ways in which Level's quarry is 'atypical,' 'peculiar,' and 'sui generis.' . . Yet without a similarly situated comparator-much less any evidence in the record of intentional discrimination by Defendants-Level's class-of-one equal protection claim must fail as a matter of law."). 
how individuals should be treated by decision makers exercising discretion:

Suppose, for example, that a traffic officer is stationed on a busy highway where people often drive above the speed limit, and there is no basis upon which to distinguish them. If the officer gives only one of those people a ticket, it may be good English to say that the officer has created a class of people that did not get speeding tickets, and a 'class of one' that did. But assuming that it is in the nature of the particular government activity that not all speeders can be stopped and ticketed, complaining that one has been singled out for no reason does not invoke the fear of improper government classification. Such a complaint, rather, challenges the legitimacy of the underlying action itself-the decision to ticket speeders under such circumstances. Of course, an allegation that speeding tickets are given out on the basis of race or sex would state an equal protection claim, because such discriminatory classifications implicate basic equal protection concerns. But allowing an equal protection claim on the ground that a ticket was given to one person and not others, even if for no discernible or articulable reason, would be incompatible with the discretion inherent in the challenged action. It is no proper challenge to what in its nature is a subjective, individualized decision that it was subjective and individualized. ${ }^{184}$

Like the police officer's decision, an insurer's decision to provide treatments for one patient but not another should not be subject to equal protection review without an allegation of inappropriate classification. ${ }^{185}$ Furthermore, in contexts like insurance where limited resources are being deployed, allowing "class of one" claims would invariably impose losses on others, frequently those greater in number but less powerful. For instance, allowing a "class of one" plaintiff to compel an insurer to provide her with brand name treatments that best cater to her unique physiology will mean that other plan participants pay higher prices for generic drugs due to a loss of economies of scale. ${ }^{186}$ The ACA should not encourage this extreme form of interest group policymaking. ${ }^{187}$ For this reason, I agree with the Employee Retirement Income Security Act (ERISA) Industry Committee's call for HHS to make clear that insurers may employ a population-wide guideline rather than needing to provide specific, tailored benefits for the needs of particular individuals. ${ }^{188}$

${ }^{184}$ Engquist v. Or. Dep't of Agric., 553 U.S. 591, $603-04$ (2008); see also Las Lomas Land Co. v. City of L.A., 177 Cal. App. 4th 837, 860 (Cal. Ct. App. 2009) (rejecting a "class of one" claim where the city had numerous legitimate reasons for choosing not to expand its boundaries).

${ }^{185}$ Cf. Endsley v. Luna, No. CV 06-04100 DSF (SS), 2009 WL 3806266, at *3 (C.D. Cal. Nov. 12 , 2009), aff'd, $473 \mathrm{~F}$. App'x 750 (9th Cir. 2012) (noting that "[a] state hospital for the mentally ill presents exactly the kind of situation identified by the Supreme Court requiring "discretionary decisionmaking based on a vast array of subjective, individualized assessments," and therefore barring patient's class of one claim).

${ }^{186}$ Cf. E. Haavi Morreim, Futilitarianism, Exoticare, and Coerced Altruism: The ADA Meets Its Limits, 25 SETON HALL L. REV. 883, 917 (1995) ("If more of the pharmaceutical budget is spent on high-cost lifesaving drugs, less of it will be available to offer a broad variety of choices for more common maladies like hypertension, arthritis, and asthma.").

${ }^{187}$ On the dangers of interest group policymaking, see generally MANCUR OLSON JR., THE LOGIC OF Collective ACTION (1965).

${ }^{188}$ Public Comment Letter from the ERISA Indus. Comm., to the Internal Revenue Serv. (Sept. 7, 2010) (on file with the Federal eRulemaking Portal), available at http://www.eric.org/forms/uploadFiles/ 2390800000106.filename.ERIC_Comments_Preventive_Services_Reg090710.pdf ("The Departments also should make clear that a plan may limit its coverage to the preventive services that are appropriate for the general population defined by the recommendations and guidelines (for example, men aged 35 and older): 


\section{b. Discrimination Against Medically Defined Classes}

Rules subjecting all patients with a given health condition to a given type of treatment come closer to violating existing antidiscrimination provisions. However, as a threshold matter, the Equal Protection Clause does not treat classifications based on health needs or illness as protected classes. Absent additional statutory law (such as the ACA), legislation disadvantaging individuals on the basis of health classifications would be subject to rational basis review. ${ }^{189}$ The Supreme Court has struck down legislation disadvantaging mentally ill individuals according to disease classifications, but on the basis that the legislation was prejudiced rather than on the basis that the classifications were protected. ${ }^{190}$ In doing so, the Court noted that

if the large and amorphous class of the mentally retarded were deemed quasi-suspect for the reasons given by the Court of Appeals, it would be difficult to find a principled way to distinguish a variety of other groups who have perhaps immutable disabilities setting them off from others, who cannot themselves mandate the desired legislative responses, and who can claim some degree of prejudice from at least part of the public at large. One need mention in this respect only the aging, the disabled, the mentally ill, and the infirm. We are reluctant to set out on that course, and we decline to do so. ${ }^{191}$

Courts have refused, for this reason, to strike down medical coverage rules as equal protection violations. ${ }^{192}$

Although the Equal Protection Clause applies mere rational basis review to legislation disadvantaging individuals along illness-based lines, statutory law (such as the ACA) can justify subjecting such legislation to more searching review by defining legislation that imposes disadvantage along illness-based classifications as violations of the statute. However, courts have also been hesitant to interpret statutory antidiscrimination language in the ADA and the Rehabilitation Act, which prohibit discrimination against people with disabilities, to prohibit benefit designs that provide different levels of coverage for patients with different conditions. In Bernard B. v. Blue Cross and Blue Shield of Greater New York, the Southern District of New York rejected plaintiffs' claim that the Rehabilitation Act barred an insurer from excluding mental health benefits from an insurance plan, stating that:

The logical consequence of plaintiffs' contention would be to mandate that, if any medical benefits were provided, there could be no benefits excluded regardless of the costs of providing the treatment in question or the preferences of the insured group. We do not believe that Congress intended to prohibit all medical insurance which was less than total in its coverage, for the necessary consequence of such a ruling would be either

the plan is not required to cover more frequent screenings or other additional services for specific individuals within that population who might be at higher risk for a particular condition (for example, a man with a family history of cardiovascular disease).").

${ }^{189}$ City of Cleburne v. Cleburne Living Ctr., 473 U.S. 432 (1985) (holding that a distinction between the mentally ill and others must be rationally related to a legitimate government purpose).

${ }^{190}$ See City of Cleburne, 473 U.S. at 450.

${ }^{191}$ Id. at $445-46$.

${ }^{192}$ E.g., Fournier v. Sebelius, 718 F.3d 1110, $1123-24$ (9th Cir. 2013), cert. denied sub nom. Berg v. Sebelius, 134 S. Ct. 1501 (2014); Lopez v. Corr. Med. Servs., No. 04-2155 (NLH), 2009 WL 1883915, at *10 (D.N.J. June 30, 2009), aff'd, 499 F. App'x 142 (3d Cir. 2012) ("The most that Lopez has alleged is that those inmates with risk factors other than HIV may not have been screened as promptly as those with HIV. There is no evidence to suggest that Defendants intentionally, and without a rational basis, singled out Lopez and refused to screen or treat just him."). 
to end all medical insurance or to require drastic reduction in the amount of allowable benefits for those risks of primary concern to the covered employees. We do not believe that the Rehabilitation Act mandates that the decision between, for example, dental or psychiatric coverage, assuming cost considerations preclude both at a reasonable benefit level, is one which cannot be left to the employer, his employees and the insurer. ${ }^{193}$

Similarly, in Alexander $v$. Choate, the Supreme Court refused to interpret the Rehabilitation Act to strike down a reduction in covered hospital days within Tennessee's Medicaid program, noting that:

... Medicaid programs do not guarantee that each recipient will receive that level of health care precisely tailored to his or her particular needs. Instead, the benefit provided through Medicaid is a particular package of health care services, such as $\mathbf{1 4}$ days of inpatient coverage. That package of services has the general aim of assuring that individuals will receive necessary medical care, but the benefit provided remains the individual services offered - not 'adequate health care.' . . . To conclude otherwise would be to find that the Rehabilitation Act requires States to view certain illnesses, i.e., those particularly affecting the handicapped, as more important than others and more worthy of cure through government subsidization. Nothing in the legislative history of the Act supports such a conclusion. Section 504 seeks to assure evenhanded treatment and the opportunity for handicapped individuals to participate in and benefit from programs receiving federal assistance. The Act does not, however, guarantee the handicapped equal results from the provision of state Medicaid, even assuming some measure of equality of health could be constructed. ${ }^{194}$

The Alexander Court went on to note that interpreting the Rehabilitation Act to produce maximal advantage for patients with specific illnesses would be both unworkable and unfair to other groups:

$[T]$ o require that the sort of broad-based distributive decision at issue in this case always be made in the way most favorable, or least disadvantageous, to the handicapped, even when the same benefit is meaningfully and equally offered to them, would be to impose a virtually unworkable requirement on state Medicaid administrators. Before taking any across-the-board action affecting Medicaid recipients, an analysis of the effect of the proposed change on the handicapped would have to be prepared. Presumably, that analysis would have to be further broken down by class of handicap - the change at issue here, for example, might be significantly less harmful to the blind, who use inpatient services only minimally, than to other subclasses of handicapped Medicaid recipients; the State would then have to balance the harms and benefits to various groups to determine, on balance, the extent to which the action disparately impacts the handicapped. In addition, respondents offer no reason that similar treatment would not have to be accorded other groups protected by statute or regulation from

${ }^{193}$ Bernard v. Blue Cross \& Blue Shield of Greater N.Y., 528 F. Supp. 125, 132-33 (S.D.N.Y. 1981), aff'd, 679 F.2d 7 (2d Cir. 1982).

${ }^{194}$ Alexander v. Choate, 469 U.S. 287, 303-04 (1985) (citations omitted). 
disparate-impact discrimination. ${ }^{195}$

Lower courts have interpreted Alexander to foreclose similar attempts to require insurers to provide coverage for individuals' or groups' specific needs. ${ }^{196}$ However, other courts have been more willing to apply antidiscrimination law to healthcare decisions that disadvantage patients with specific diseases. The Eighth Circuit compelled an insurer to provide coverage in Henderson v. Bodine Aluminum, Inc., holding that "if the evidence shows that a given treatment is non-experimental-that is, if it is widespread, safe, and a significant improvement on traditional therapiesand the plan provides the treatment for other conditions directly comparable to the one at issue, the denial of that treatment arguably violates the ADA.."197 And the Ninth Circuit held in Rodde $v$. Bonta that a locality could not close a hospital that treats patients with disabilities while leaving other hospitals open. ${ }^{198}$

There have also been debates about priority setting at the level of physicians and hospitals. Several courts have refused to interpret the ADA and the Rehabilitation Act's antidiscrimination provisions to require hospitals to treat patients with specific illnesses, such as infants and adults with disabilities ${ }^{199}$ and patients with HIV ${ }^{200}$ or to provide patients with disabilities with legal remedies for nontreatment or negligent treatment related to their disabling illness. ${ }^{201}$ However, other courts have been more willing to step in, for instance, to indicate that the ADA requires the treatment of an anencephalic infant, and would also require a hospital to ignore the fact that a patient is likely to die of other causes when deciding whom to treat, ${ }^{202}$ or provide recourse

${ }^{195} \mathrm{Id}$. at 308 .

${ }^{196}$ Cohon ex rel. Bass v. N.M. Dep't of Health, 646 F.3d 717, 726-27 (10th Cir. 2011) (rejecting claim that Medicaid benefits sufficient "to serve the interests of the Medicaid population as a whole" but insufficient for plaintiff's needs constituted a Rehabilitation Act violation); Doe v. Mut. of Omaha Ins. Co., 179 F.3d 557, 560 (7th Cir. 1999), cert. denied, 528 U.S. 1106 (2000) (rejecting claim that caps on treatment for AIDS-related illnesses violate the ADA); Lenox v. Healthwise of Ky., Ltd., 149 F.3d 453, 457 (6th Cir. 1998) (rejecting claim that a "plan violates the ADA because it covers some types of transplants, but not heart transplants"); Modderno v. King, 871 F. Supp. 40, 43 (D.D.C. 1994), aff'd, 82 F.3d 1059 (D.C. Cir 1996), cert. denied, 519 U.S. 1094 (1997) (rejecting claim that differences in benefits violate the Rehabilitation Act).

${ }^{197}$ Henderson v. Bodine Aluminum, Inc., 70 F.3d 958, 960 (8th Cir. 1995).

198 Rodde v. Bonta, 357 F.3d 988, 997 (9th Cir. 2004); see also Doe, 179 F.3d at 565 (Evans, J., dissenting).

${ }^{199}$ Bowen v. Am. Hosp. Ass'n, 476 U.S. 610, 647 (1986) (Stevens, J., plurality opinion) ("Section 504 does not authorize the Secretary to give unsolicited advice either to parents, to hospitals, or to state officials who are faced with difficult treatment decisions concerning handicapped children."); Schiavo ex rel. Schindler v. Schiavo, 403 F.3d 1289, 1294 (11th Cir. 2005), reh'g denied en banc, 404 F.3d 1270 (11th Cir. 2005); reh'g denied, 404 F.3d 1282 (11th Cir. 2005); stay denied, 544 U.S. 957 (2005) ("The Rehabilitation Act, like the ADA, was never intended to apply to decisions involving the termination of life support or medical treatment"); United States v. Univ. Hosp., State Univ. of N.Y. at Stony Brook, 729 F.2d 144, 157 (2d Cir. 1984) (rejecting the suggestion that a medical judgment not to treat a newborn with a disability constituted discrimination under the $\mathrm{ADA}$, in part because antidiscrimination principles are inappropriate when applied to medical judgments); see also Wagner ex rel. Wagner v. Fair Acres Geriatric Ctr., 49 F.3d 1002, 1012 (3d Cir. 1995) (noting that Bowen and University Hospital refused to apply the ADA's antidiscrimination provisions to "medical treatment cases involving handicapped infants which necessitate complex assessments of the medical needs, benefits and risks of providing invasive medical care").

${ }^{200}$ Lesley v. Chie, 81 F. Supp. 2d 217, 224 (D. Mass. 2000), aff d, 250 F.3d 47 (1st Cir. 2001) (holding that the Rehabilitation Act "is not meant to apply to medical treatment decisions").

${ }^{201}$ Burger v. Bloomberg, 418 F.3d 882, 883 (8th Cir. 2005) ("[A] lawsuit under the Rehab[ilitation] Act or the Americans with Disabilities Act (ADA) cannot be based on medical treatment decisions.") Fitzgerald v. Corr. Corp. of Am., 403 F.3d 1134, 1144 (10th Cir. 2005) (stating that "neither the ADA nor the Rehabilitation Act provide remedies for alleged medical negligence," and collecting cases)

${ }^{202}$ In re Baby K, 832 F. Supp. 1022, 1028 (E.D. Va. 1993), aff'd, 16 F.3d 590 (4th Cir. 1994) (suggesting that "an AIDS patient seeking ear surgery is "otherwise qualified' to receive treatment despite poor long term prospects of living"); see also Bowen, 476 U.S. at 656-57 (White, J., dissenting) ("That some 
under the Rehabilitation Act for medical judgments that are capricious or reflect stereotypes about individuals with certain medical conditions. ${ }^{203}$

In a 2011 law review article, Wendy Hensel and Leslie Wolf argue that courts should be willing to critically review meso-level and macro-level policies set by governments and insurers to consider whether these policies are responsive to the needs of particular individuals. ${ }^{204}$ The authors maintain that courts should not apply federal antidiscrimination law (as opposed to state tort and malpractice law) to microlevel, individualized priority-setting decisions, such as physicians' judgments as to how specific patients should be treated. ${ }^{205}$ In support of this claim, Hensel and Wolf point to an unpublished Department of Justice opinion suggesting that physicians would violate the ADA by categorically excluding a patient with Down syndrome from access to organ transplantation rather than engaging in "an individualized assessment of her actual abilities." ${ }^{206}$ Some have similarly argued that organ transplantation eligibility rules should be revised to require individual assessment of medical condition by a physician, ${ }^{207}$ and California and New Jersey have in fact adopted laws to this effect. ${ }^{208}$

The suggestion that physicians' individualized judgments warrant greater

or most failures to treat may not fall within $\S 504$, that discerning which failures to treat are discriminatory may be difficult, and that applying $\S 504$ in this area may intrude into the traditional functions of the State do not support the categorical conclusion that the section may never be applied to medical decisions about handicapped infants."); Univ. Hosp., State Univ. of N.Y. at Stony Brook, 729 F.2d at 162 (Winter, J., dissenting) (" $[\mathrm{A}]$ decision not to correct a life threatening digestive problem because an infant has Down's Syndrome is not a bona fide medical judgment.").

${ }^{203}$ See Lesley, 250 F.3d at 55; see also Glanz v. Vernick, 756 F. Supp. 632, 638 (D. Mass. 1991) ("A strict rule of deference would enable doctors to offer merely pretextual medical opinions to cover up discriminatory decisions."); Glanz v. Vernick, 750 F. Supp. 39, 46 (D. Mass. 1990) (finding, notwithstanding University Hospital, that plaintiff stated a claim for relief under the Rehabilitation Act by alleging that his medical treatment was "denied because of unjustified consideration of . . . handicap").

${ }^{204}$ Wendy F. Hensel \& Leslie E. Wolf, Playing God: The Legality of Plans Denying Scarce Resources to People with Disabilities in Public Health Emergencies, 63 FLA. L. REV. 719,747 (2011) ("The cases declining to review medical treatment decisions generally require scrutiny of professional judgment rendered to a specific individual without predetermined limitations as to what care may be provided. Because the professional's decision pertains to and can be evaluated in the context of a particular patient and his actual need for treatment, it is necessarily based, at least to some extent, on an individualized determination as mandated by the ADA. It may be that once this threshold is crossed, the legitimacy and reasonableness of medical decisions are most appropriately evaluated in the context of state tort law and professional standards of care, rather than in the context of antidiscrimination laws. In contrast, sweeping policies that preclude or significantly limit entire categories of people with disabilities from receiving medical care in advance of actual need necessarily are based on generalizations concerning status. Their legitimacy depends on whether scientific evidence establishes that no individual in the excluded class could possibly qualify for or benefit from the medical treatment at issue, or whether the exclusionary criteria is actually based on prejudicial stereotypes and myths. It is precisely this type of inquiry that Congress intended to reach through the ADA and the Rehabilitation Act, and such policies should be subject to judicial review." (footnotes omitted)).

${ }^{205} I d$.

${ }^{206}$ Id. at 748; see also Mary Crossley, Becoming Visible: The ADA's Impact on Health Care for Persons with Disabilities, 52 ALA. L. REV. 51, 65 (2000) (describing "the case of Sandra Jensen, a woman with Down syndrome who developed a need for a heart and lung transplant").

${ }^{207}$ Danielle Richards, Note, The Defibrillation of NOTA: How Establishing Federal Regulation of Waitlist Eligibility May Save Organ Transplant Patients with Disabilities from Flat-Lining, 87 S. CAL. L. REV. 151, 187 (2013) (endorsing the "importance of individual evaluation of transplant candidates to determine their postoperative compliance abilities"); Angela T. Whitehead, Note, Rejecting Organs: The Organ Allocation Process and the Americans with Disabilities Act, 24 AM. J.L. \& MED. 481, 495 (1998) (arguing that UNOS should "consider a patient's candidacy based on his or her own characteristics and capabilities" rather than adopting categorical rules).

${ }^{208}$ CAL. Health \& SAFETy CODE $\$ 7151.35$ (West 2007); N.J. Stat. ANN. $§ 26: 6-86.2$ (West 2007); see also Richards, supra note 207, at 188-90 (discussing these statutes). 
deference than higher level priority-setting choices is particularly interesting because it inverts the frequent suggestion that priority-setting decisions that may disadvantage specific patients or groups of patients should be made at the insurer or governmental level, rather than by individual physicians, in order to safeguard the physician-patient relationship and protect physicians from experiencing divided loyalties. ${ }^{209}$ However, the Supreme Court has suggested that courts applying antidiscrimination law should defer not only to physicians' medical judgments (which, as Hensel and Wolf suggest, frequently reflect an individualized assessment of patients' needs ${ }^{210}$ ), but also to "the judgments of public health officials in determining whether an individual is otherwise qualified unless those judgments are medically unsupportable."211 Public health, unlike clinical medicine, has as its emblem precisely the sort of broad-spectrum, societal, non-individualized interventions (from water fluoridation to iodized salt to bans on secondhand smoke) that may have differential impacts on individuals with different needs, and which Hensel and Wolf criticize. ${ }^{212}$

There is not yet sufficient case law to provide a sense of how courts will view the ACA's antidiscrimination provisions, and in particular whether they will interpret these provisions to mandate the provision of insurance coverage or medical care to individuals with specific illnesses, as courts have been reluctant to do where the ADA and the Rehabilitation Act are concerned. ${ }^{213}$ Some, however, have already called for such an interpretation. A group of researchers at the Georgetown University Health Policy Institute recently argued:

Prior to the ACA, federal and state law included some nondiscrimination protections, but most have had only a limited effect in ensuring that coverage meets the needs of all consumers. Through its broad incorporation of new standards, the ACA is designed to address this gap by prohibiting discrimination based on health status, disability, age, race, gender, and sexual orientation, among other factors. In preventing discrimination against certain groups - and, in particular, the sick - the ACA takes significant steps towards ensuring that private health insurance meets the needs of the most vulnerable. ${ }^{214}$

They go on to state that " $[\mathrm{b}] \mathrm{y}$ prohibiting insurers from offering coverage that discriminates based on race, national origin, sex, age, disability, gender identity, sexual orientation, expected length of life, or significant health needs, the ACA represents a significant shift away from many existing discriminatory practices." ${ }^{215}$ Although I agree with these authors that existing antidiscrimination law has not substantially ensured that coverage meets every customer's needs, I am less certain either descriptively that the ACA ensures this outcome or normatively that such an outcome

${ }^{209}$ See Hall, supra note 12, at 703-11 (reviewing opposition to priority setting at the physician level).

${ }^{210}$ See Hensel \& Wolf, supra note 204, at 744-50.

${ }^{211}$ Sch. Bd. of Nassau Cnty., Fla. v. Arline, 480 U.S. 273, 286 n.15 (1987); cf. Robert J. Moossy, Jr., Comment, Health Care Prioritization and the ADA: The Oregon Plan 1991-1993, 31 Hous. L. REV. 265, 316-17 (1994) ("Within the scope of an entitlement program such as Medicaid, however, the decision of what benefits to provide rests with public health officials so long as they are truly exercising their professional judgment in a reasonable manner. It is part of a public health care professional's job to assess treatment options and then decide, using their medically based health care judgment, whether that treatment warrants implementation." (footnotes omitted)).

${ }^{212}$ See Hensel \& Wolf, supra note 204, at 724-28.

${ }^{213}$ E.g., Alexander v. Choate, 469 U.S. 287, $303-04$ (1985); Doe v. Mut. of Omaha Ins. Co., 179 F.3d 557, $563-64$ (7th Cir. 1999); Modderno v. King, 871 F. Supp. 40, $42-43$ (D.D.C. 1994).

${ }^{214}$ KEITH ET AL., supra note 174, at 4.

${ }^{215} \mathrm{Id}$. at 9. 
would be desirable.

Others, conversely, have argued that the ACA's incorporation of the Rehabilitation Act and other antidiscrimination law into its text already serves to bar insurance designs that disadvantage patients and subgroups. An HIV advocacy group, for instance, recently argued:

If single pill regimen antiretroviral therapy is excluded from a formulary, for example, the necessity of reverting to a multi-pill regimen may result in an increase in side effects and a lowered rate of compliance. This, in effect, is a prohibited discrimination based on a disability - in this case, HIV - that falls under the purview of the exchange regulator to address. This sort of activity is prohibited under rules against benefit design discrimination and under Section 1557.216

At least with respect to section 1557, which incorporates the Rehabilitation Act and other antidiscrimination law, this suggestion is incorrect. Doe v. Mutual of Omaha clearly states that the Rehabilitation Act does not prohibit insurance designs that in practice disadvantage patients with HIV ${ }^{217}$ The question is whether the ACA's new provisions concerning health status discrimination legislatively override Doe as applied to health insurers.

Waiting periods represent one area where specific guidance has already been issued. Commenters on an Oregon statute complained that a twenty-four-month waiting period for organ transplants violates the ACA's anti-discrimination provisions. ${ }^{218}$ During May 2014, Centers for Medicare and Medicaid Services (CMS) issued guidance expressing concern that "waiting periods for specific benefits discourage enrollment of or discriminate against individuals with significant health needs or present or predicted disability," and stating that "a plan that includes a waiting period for any type of transplant would discriminate against those whose conditions make it likely that they would need a transplant: those with kidney disease, heart conditions, or similarly critical and life-threatening ailments. ${ }^{219}$ CMS went on to state that "with respect to plans that must provide coverage of the essential health benefit package, issuers may not impose benefit-specific waiting periods, except in covering pediatric orthodontia, in which case any waiting periods must be reasonable pursuant to section 156.125."220 CMS did also provide that "[t]his clarification refers to a waiting period that is applied uniformly to a specific benefit within the plan design and not reasonable medical management," 221 thus leaving open whether waiting periods that are part of evidence-based guidelines or medical custom would be acceptable under section 156.125 .

\footnotetext{
216 Joshua L. Holmes, Human Rights and Health Care Exchanges: Affordable Care Act's Antidiscrimination Provisions, HIV CLINICIAN, Winter 2014, at 1,2 , available at http://www.deltaaetc.org/hcarticles/articles\%20as\%20pdf/winter\%202014\%20articles\%20as\%20pdf/ACA\% 20antidiscrimination $\% 20$ provisions.pdf.

${ }^{217}$ Mut. of Omaha Ins. Co., 179 F.3d at 560, cert. denied,

528 U.S. $1106(2000)$.

${ }^{218}$ Letter from Alan Langnas, President, Am. Soc'y of Transplant Surgeons, and Daniel R. Salomon, President, Am. Soc'y of Transplantation, to Laura Cali, Ins. Comm'r, Or. Dept. of Consumer Bus. Servs. (Dec. 6, 2013) (on file with author), available at http://asts.org/docs/default-source/regulatory/asts-and-astcomments-to-oregon-insurance-division-december-9-2013.pdf

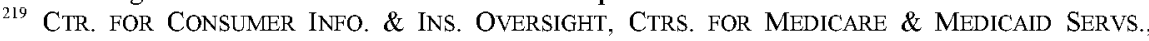
FREQUENTLY ASKED QUESTIONS ON HEALTH INSURANCE MARKET REFORMS AND MARKETPLACE STANDARDS 1 (2014), available at http:/www.cms.gov/CCIIO/Resources/Fact-Sheets-andFAQs/downloads/Final-Master-FAQs-5-16-14.pdf.

${ }^{220} I d$. at 2.

${ }^{221} \mathrm{Id}$.
} 
CMS's opinion represents a major departure from pre-ACA court decisions regarding insurance coverage, which were reluctant to strike down coverage decisions that were uniformly applied, even when they worked to the disadvantage of some patients. ${ }^{222}$ Courts have hitherto been highly deferential to the judgments of physicians and hospitals when considering what constitutes appropriate treatment of a medically defined class-what medicine gives, medicine can take away. ${ }^{223}$ CMS's opinion suggests that HHS, at least, is willing to intervene more aggressively in priority-setting decisions to ensure that medically defined classes are not disadvantaged. This stance has been welcomed by disease advocacy groups charging that "individuals with highcost chronic and acute conditions like cancer" are those at the greatest risk of discrimination. ${ }^{224}$ However, CMS leaves the justification for its position ambiguous when it notes that waiting periods "discourage enrollment of or discriminate against" patients with specific illnesses. The "discourage enrollment" language suggests concern that private insurers will cherry-pick cheaper, healthier customers by failing to provide benefits, such as transplants, sought by sicker, more costly patients. In such a scenario, the cherry-picking insurers would be displacing the cost of treating sicker patients onto their competitors in the market or onto government-provided plans of last resort. ${ }^{225}$ Such conduct would be inconsistent with the ACA's goal of expanding access to healthcare. ${ }^{226}$ However, the "discourage enrollment" language would not justify prohibiting waiting periods within Medicaid plans such as Oregon's. Such waiting periods do not deter the enrollment of patients needing transplants, since they have no alternative to Medicaid. Rather, they impose a burden on patients needing transplants in order to control costs and provide benefits to other plan participants. Such a priority-setting decision involves a value judgment, but not obviously an inappropriate one, particularly when refusing to impose a waiting period would disadvantage other-perhaps less visible-Medicaid beneficiaries, such as children needing preventive care. CMS would be making a mistake if it employed the "discriminate against" language to classify waiting periods within Medicaid or Medicare as impermissible discrimination.

CMS is also attempting to assess whether plans are employing discriminatory benefit designs by conducting an "outlier analysis": Arkansas's regulations note that "[w]ith respect to prescription drugs, CMS has indicated they intend to review plans that are outliers based on an unusually large number of drugs subject to prior authorization and/or step therapy requirements in a particular category and class."227

${ }^{222}$ See Orentlicher, supra note 118, at 78-81 (discussing Alexander v. Choate and its implications).

${ }^{223}$ Margaret Gilhooley, Broken Back: A Patient's Reflections on the Process of Medical Necessity Determinations, 40 VILL. L. REV. 153, 161-62 (1995).

${ }^{224}$ Public Comment Letter from the Patients Equal Access Coal., to Kathleen Sebelius, Sec'y, Dep't of Health \& Human Servs. (Dec. 21, 2012) (on file with the National Brain Tumor Society), available at http://www.braintumor.org/assets/docs/advocate-for-change/alerts-polls-

updates/2012_final_peac_speac_comment_letter_on_ehb_proposed_rule_11_11_13.pdf.

${ }^{225}$ However, the ACA's provision for "risk corridors" that pay insurers bonuses for covering high-risk patients attempts to prevent this outcome. See KAISER FAMILy Found., EXPLAINING HEALTH CARE REFORM: RISK ADJUSTMENT, REINSURANCE, AND RISK CORRIDORS 8-9 (2014), available at $\mathrm{http://kff.org/health-reform/issue-brief/explaining-health-care-reform-risk-adjustment-reinsurance-and-risk-}$ corridors/.

${ }^{226}$ Cf. Letter from James H. Scully, Jr., Med. Dir. \& CEO, Am. Psychiatric Ass'n, to Ctr. for Consumer Info. \& Ins. Oversight (Mar. 15, 2013) (on file with author), available at http://www.psychiatry.org/File\%20Library/Advocacy\%20and\%20Newsroom/APA\%20on\%20the\%20Issues /Regulatory/3-15-13-Final-Letter-to-Issuers-on-Federally-facilitated-and-State-Partnership-Exchanges.pdf ("The primary goal of health reform is to provide health care access to a greater number of Americans. The ACA's nondiscrimination provisions remain central to being able to achieve this goal.").

${ }^{227}$ Memorandum from the Arkansas Insurance Department to All Licensed Insurers et al. 15 (Apr. 11 , 
The outlier analysis approach is better grounded than blanket bans on priority-setting efforts such as waiting periods, because it limits cherry-picking without impinging on cost control. If a plan is subjecting an unusual number of drugs for a given condition to prior authorization or step therapy, in comparison to other plans, this at least suggests that the plan is attempting to discourage the enrollment of unhealthy individuals. ${ }^{228}$ But if all plans are subjecting drugs for a certain condition to prior authorization, while this may be disadvantageous for the condition's sufferers, it does not saddle any one plan disproportionately with the costs of treating a costly condition and thus concern is lessened that a single plan is cherry-picking customers.

CMS has also suggested additional ways in which it plans to prevent the use of discriminatory benefit designs. CMS's 2014 Letter notes that "CMS also intends to propose in future rulemaking a review of prescription drugs based on clinical appropriateness that states may choose to implement." 229 CMS also notes that it will scrutinize plans for "[d]iscriminatory cost-sharing language," which "would typically involve reduction in the generosity of a benefit in some manner for subsets of individuals other than based on clinically indicated common medical management practices." ${ }^{230}$ Like the restriction on waiting periods, this provision is ambiguous in its justification, although its placement within a section that begins with a discussion of practices that discourage the enrollment of ill patients may suggest that this scrutiny would also focus on cherry-picking rather than on disadvantage to specific subsets.

\section{c. Discrimination Against Protected Classes}

Other priority-setting decisions may target classes that are not defined in terms of a medical condition. Some worry about discrimination against children, whose medical care is frequently low cost but has delayed benefits. ${ }^{231}$ Similarly, the National Health Law Program has argued that "in the context of contraceptive care, medical management techniques that limit, delay or deny coverage of a woman's chosen FDAapproved method are never permissible," and that HHS should issue additional

2014) (on file with author), available at $\mathrm{http} / / \mathrm{www}$.insurance.arkansas.gov/Legal/Bulletins/9-2014.pdf; see also Memorandum from Todd E. Kiser, Comm'r, Utah Insurance Dep't, to Insurance Carriers Offering Health Benefit Plans or Stand-Alone Dental Plans 8 (Mar. 4, 2014), available at https://insurance.utah.gov/legal-resources/bulletins/documents/2014-3-Signed.pdf (similar).

${ }^{228}$ CMS's 2014 Letter to Issuers in the Federally-Facilitated Marketplaces affirms that the purpose of outlier analysis is to prevent cherry-picking. Memorandum from Ctr. for Consumer Info. \& Ins. Oversight, Ctrs. for Medicare \& Medicaid Servs. to Issuers in the Federally-Facilitated Marketplaces 28 (March 14, 2014) (on file with author), available at http://www.cms.gov/CCIIO/Resources/Regulations-andGuidance/Downloads/2015-final-issuer-letter-3-14-2014.pdf [hereinafter Final Memorandum] ("In addition to complying with EHB non-discrimination standards, [Qualified Health Plans (QHPs)] must not employ market practices or benefit designs that will have the effect of discouraging the enrollment of individuals with significant health needs. To ensure non-discrimination in QHP benefit design, CMS will perform an outlier analysis on QHP cost sharing (e.g., co-payments and co-insurance) as part of the QHP certification application process. QHPs identified as outliers may be given the opportunity to modify cost sharing for certain benefits if CMS determines that the cost sharing structure of the plan that was submitted for certification could have the effect of discouraging the enrollment of individuals with significant health needs." (citations omitted)).

${ }^{229}$ Draft Memorandum from Ctr. for Consumer Info. \& Ins. Oversight, Ctrs. for Medicare \& Medicaid Servs. to Issuers in the Federally-Facilitated Marketplaces 30 (Feb. 4, 2014) (on file with author), available at http://www.cms.gov/CCIIO/Resources/Regulations-and-Guidance/Downloads/draft-issuer-letter-2-42014.pdf.

${ }^{230}$ Final Memorandum, supra note 228, at 29.

${ }^{231}$ Patience White, Testimony on Behalf of the American Academy of Pediatrics Before the U.S. Department of Health and Human Services (Oct. 18, 2011), available at http://www.aap.org/enus/advocacy-and-policy/federal-advocacy/Documents/Patience_White_Testimony_10-18-11.pdf. 
guidance to this effect. ${ }^{232}$ The National Women's Law Center has suggested that, "while the [essential health benefits] rule states these requirements do not prevent issuers from 'appropriately utilizing reasonable medical management techniques,' these techniques cannot be used in ways that discriminate. ${ }^{" 233}$ However, the language of the regulation suggests that if a technique is reasonable, then it by definition does not discriminate, even if it may disadvantage some patients.

In response to the regulations' lack of clarity about whether they permit prioritysetting decisions that work to the disadvantage of protected classes, the Family Equality Council expressed concern about devolving all enforcement to states, and called on CMS to "develop a clear standard for what constitutes a discriminatory benefit design." ${ }^{234}$ More specifically, the Council called for a broad definition of what constitutes a discriminatory benefit:

This standard must address both individual cases of intentional discrimination and benefit designs that are facially neutral but that have the effect of systematically disadvantaging members of protected classes. Ultimately, this standard must make clear that the determination of whether a coverage limitation or exclusion is discriminatory should turn on the degree to which the benefit design is based on sound standards of clinical appropriateness rather than on arbitrary distinctions between health conditions or personal characteristics. To assist federal and state regulators and insurance carriers in rectifying discrimination in benefit design, CMS should follow up on the final rule with subregulatory guidance explaining how to evaluate products for impermissible discrimination and providing examples of discriminatory benefit designs such as those listed above. In addition, CMS should require trained evaluators in each state to regularly and transparently review insurance contracts for discriminatory benefit designs and to ensure that issuers act quickly to remedy identified instances of discrimination. Where CMS determines that a state is not fulfilling its responsibilities in this area, CMS should establish a review procedure that goes beyond existing procedures for Medicare Advantage and Medicare Part D to focus on ensuring that all services deemed part of the essential benefits are available to all eligible individuals for whom they are medically necessary, without arbitrary discrimination on the basis of any protected personal characteristic. ${ }^{235}$

The Council's call for enforcement procedures that assess "clinical appropriateness" and medical necessity recalls Rosenbaum's suggestion that HHS rely on clinical judgment when deciding when the consideration of a factor is discriminatory. ${ }^{236}$

${ }^{232}$ Erin Armstrong, Medical Management and Access to Contraception, NAT'L HEALTH L. PROGRAM (May 1, 2013), http://www.healthlaw.org/publications/medical-management-and-access-to-contraception.

233 NATIONAL WOMEN'S LAW CENTER, AN OVERVIEW OF SECTION 1557, NONDISCRIMINATION STANDARDS, AND THE AFFORDABLE CARE ACT: A TOOL FOR STAKEHOLDERS 7 (2013) (footnote omitted), available at http://www.nwlc.org/resource/overview-section-1557-nondiscrimination-standards-andaffordable-care-act-tool-stakeholders.

${ }^{234}$ Public Comment Letter from Jennifer Chrisler, Exec. Dir., Family Equal. Council, to Ctrs. for Medicare \& Medicaid Servs., Dep't of Health \& Human Servs. (Dec. 20, 2012) (on file with author), available at $\mathrm{http}$ :/Www.familyequality.org/ asset/cst5jd/Family-Equality-Council-Comments-for-HHSEHB-Proposed-Rule-12_20.pdf. The Family Equality Council is a lesbian, gay, bisexual and transgender advocacy group. Id.

${ }^{235} \mathrm{Id}$.

${ }^{236}$ INST. OF MEDICINE, supra note 139 , at 87. 
However, its discussion of "benefit designs that are facially neutral but that have the effect of systematically disadvantaging members of protected classes"237 draws attention to a challenge that antidiscrimination statutes have systematically facedwhether they only target intentional discrimination, or also reach what is called "disparate impact." 238 The Supreme Court has been increasingly hesitant to find in favor of plaintiffs alleging disparate impact under a variety of antidiscrimination statutes. ${ }^{239}$ It is unclear whether the ACA's antidiscrimination language will form an exception to this trend, or instead continue it.

\section{Additional Regulations on Plans OfFered Through Exchanges}

While the Essential Health Benefit provisions discussed above apply to plans offered through Exchanges, the ACA also contains two sections that further regulate plans offered through the Exchanges.

\section{Preventing Death at Any Cost}

First, the ACA prohibits Exchanges from excluding plans "on the basis that the plan provides treatments necessary to prevent patients' deaths in circumstances the Exchange determines are inappropriate or too costly."240 This provision has limited scope. At least on its face, it does not require that plans provide treatments necessary to prevent patients' deaths, nor does it exempt plans from having to provide essential health benefits or meet the other requirements that Exchanges impose. ${ }^{241}$ If plans are providing costly lifesaving treatments, then they are affording this either by reducing their profits, raising premiums, or cutting benefits elsewhere. All these choices are perfectly acceptable - at least in a competitive marketplace-as patients can take their business elsewhere if they prefer lower premiums or more generous benefits at the expense of heroic treatments for rare, costly diseases.

However, if this language were interpreted to allow plans to fail to provide essential health benefits, or to exempt programs from the ACA's other regulations on health plans, it could pose problems. Such a conflict could arise if providing costly lifesaving treatments led to a provider receiving low scores on clinical quality measures, if doing so interfered with the pursuit of quality improvement, or if a benefit design that provided such treatments discouraged the enrollment of individuals with serious health needs. The last might initially seem improbable, but such a scenario is possible if, for instance, a plan prominently offered a costly lifesaving treatment for rare childhood diseases, one that might be of little value to older patients with chronic conditions that cost the insurer more to treat. ${ }^{242}$

Another effect of this provision is that it would limit Exchanges' efforts to apply

${ }^{237}$ Chrisler, supra note 234.

${ }^{238}$ Ricci v. DeStefano, 557 U.S. 557, 577 (2009) ("Title VII prohibits both intentional discrimination (known as 'disparate treatment') as well as, in some cases, practices that are not intended to discriminate but in fact have a disproportionately adverse effect on minorities (known as "disparate impact").").

${ }^{239}$ See Ian Haney-Lopez, Intentional Blindness, 87 N.Y.U. L. REV. 1779, 1781 n.3 (2012) (collecting examples); see also Ricci, 557 U.S. at 594 (Scalia, J., concurring) ("Whether, or to what extent, are the disparate-impact provisions of Title VII of the Civil Rights Act of 1964 consistent with the Constitution's guarantee of equal protection?").

${ }^{240} 42$ U.S.C. $\$ 18031(\mathrm{e})(1)(\mathrm{B})(\mathrm{iii})(2012)$

${ }^{241} I d$.

${ }^{242}$ Cf. Lior Jacob Strahilevitz, Exchusionary Amenities in Residential Communities, 92 VA. L. REV. 437 (2006) (noting that costly amenities can serve to exclude disadvantaged individuals from community membership). 
traditional cost-effectiveness analysis as a cutoff for which plans are included as qualified health plans: even if preventing deaths via costly treatments reduces a plan's cost-effectiveness, Exchanges may not use that fact as a reason to exclude a plan. ${ }^{243}$ However, Exchanges may still use effectiveness and cost-effectiveness data to provide consumers with information. ${ }^{244}$ For example, the same section of the ACA also provides that the Secretary "shall develop a rating system that would rate qualified health plans offered through an Exchange in each benefits level on the basis of the relative quality and price," and "shall include the quality rating in the information provided to individuals and employers." ${ }^{245}$ These price-quality ratings could employ traditional cost-effectiveness data, even if they led to plans that offer costly lifesaving care receiving lower ratings, since the data is not being used to block access to plans, but to inform consumers about the different options available within different plans.

Finally, the language employed here-that of "preventing death"-is notable. Medical treatments can extend life, but they cannot, ultimately, prevent death. The idea of a clear cutoff between treatments that prevent death and those that do not is dubious. While a very few treatments may improve quality of life without increasing its length, many others serve to extend the length of life. Placing special importance on preventing imminent death serves to endorse what Albert Jonsen calls the "Rule of Rescue," which places special importance on saving someone from imminent death, regardless of the cost and, perhaps more importantly, regardless of whether that person will then be in stable health or will instead be menaced by other health problems. ${ }^{246}$ While this principle is frequently embraced in practice, it has also been frequently criticized as an inappropriate and wasteful method of distributing scarce resources. ${ }^{247}$

\section{Clinical Trials and "Life-Threatening Conditions"}

The second provision that prioritizes the prevention of imminent death refers to clinical trials. ${ }^{248}$ It requires that health insurance plans not deny individuals participation in certain clinical trials, nor discriminate against individuals who participate in such trials, and that they receive coverage for routine costs associated with trial participation. ${ }^{249}$ However, the language requires only that patients be allowed, without disadvantage, to participate in "a phase I, phase II, phase III, or phase IV clinical trial that is conducted in relation to the prevention, detection, or treatment of cancer or other life-threatening disease or condition." ${ }^{, 250}$ It defines a life-threatening condition as "any disease or condition from which the likelihood of death is probable unless the course of the disease or condition is interrupted."251

Yet there are many serious medical conditions that do not fall under this category,

${ }^{243} 42$ U.S.C. $\$ 18031(\mathrm{e})(1)(\mathrm{B})(\mathrm{iii})$ (2012).

${ }^{244} 42$ U.S.C. $\$ 18031(\mathrm{c})(3)$.

${ }^{245} \mathrm{Id}$.

${ }^{246}$ Albert R. Jonsen, Bentham in a Box: Technology Assessment and Health Care Allocation, $14 \mathrm{~L}$ MED. \& HEALTH CARE 172, 174 (1986).

${ }^{247}$ See Persad et al., supra note 11, at 424-25; see also Leonard M. Fleck, Last Chance Therapies: Can a Just and Caring Society Do Health Care Rationing When Life Itself is at Stake?, 2 YALE J. HEALTH POL'Y L. \& ETHICS 255, 275 (2002) (noting that "[i]f all . . individuals could make themselves visible victims of rationing in need of rescue, it would subvert all just schemes of health care rationing, including last chance therapies.").

${ }^{248} 42$ U.S.C. $\$ 300 \mathrm{gg}-8$.

${ }^{249} 42$ U.S.C. $\S 300 g g-8(a)(1)(A)-(C)$.

${ }^{250} 42$ U.S.C. $\$ 300 \mathrm{gg}-8(\mathrm{~d})(1)$.

${ }^{251} 42$ U.S.C. $\$ 300 \mathrm{gg}-8(\mathrm{e})$ 
including communicable diseases like human papilloma virus (HPV), ${ }^{252}$ neurological conditions like autism, ${ }^{253}$ and other conditions such as chronic pain. ${ }^{254}$ Indeed, some of these conditions are arguably more serious and pressing healthcare priorities than some life-threatening conditions. For instance, untreated heart arrhythmia will almost certainly lead to imminent death, but we have a sound grasp on effective treatments, namely pacemakers. ${ }^{255}$ However, while autism does not "lead to death unless interrupted," we have no idea how to effectively treat it, and it can impose serious burdens on individuals with autism and their families. ${ }^{256}$ Research on interventions for autism is therefore almost certainly more important than research on alternative treatments for heart arrhythmias. Yet the ACA's emphasis on preventing imminent death seemingly permits healthcare plans to deny patients with non-life-threatening conditions access to clinical trials that could benefit them and could also advance the development of treatments for those conditions. By prioritizing life-threatening conditions over communicable diseases or chronic and painful illnesses, this provision imposes a top-down set of priorities that does not necessarily reflect scientific or medical expertise, cost-effectiveness, clinical effectiveness, or the values of patient communities. Indeed, on the expansive understanding of discrimination that CMS's prohibition on waiting periods suggests, this prohibition might discriminate against patients with serious conditions that are not life-threatening.

\section{ACHIEVING COST CONTROL AND QUALITY IMPROVEMENT WITHIN THE ACA'S LIMITS}

While the ACA, as I have argued, likely goes too far in limiting the use of traditional cost-effectiveness analysis, it also offers an opportunity for healthcare funders and decision makers to think innovatively about how to control costs and improve quality without falling afoul of the ACA's requirements. In this section, I consider three aspects of the ACA: (1) its emphasis on fairness to people with disabilities; (2) its discussion of age weighting; and (3) its antidiscrimination provisions. Additionally, I propose ways that healthcare priority setting can change in order to take these requirements into account.

\section{A. DISABILITY}

Rather than attempting to use traditional cost-effectiveness analysis in combination with other factors and to avoid the "threshold" language, PCORI could treat the restrictions as an opportunity to design a unit of measurement for costeffectiveness that does not disadvantage people with disabilities.

The challenge for those attempting to improve cost-effectiveness while not disadvantaging people with disabilities is to achieve these three goals:

a) Prioritize treatments that improve length of life;

b) Prioritize treatments that cure disabling conditions, or prevent people

252 Human papillomavirus (HPV) and cervical cancer, WORLD HEALTH ORG. http://www.who.int/mediacentre/factsheets/fs380/en (last updated Nov. 2014).

${ }^{253}$ Autism Fact Sheet, NAT"L InST. NEUROLOGICAL DISORDERS \& STROKE, http $/ /$ www.ninds.nih.gov/ disorders/autism/detail_autism.htm (last updated Nov. 6, 2014) [hereinafter Autism Fact Sheet].

${ }^{254}$ NINDS Chronic Pain Information Page, NAT'L Inst. NEURological Disorders \& STROKE, http://www.ninds.nih.gov/disorders/chronic_pain/chronic_pain.htm (last updated Dec. 18, 2014).

${ }^{255}$ See François Roubille \& Jean-Claude Tardif, New Therapeutic Targets in Cardiology-Heart Failure and Arrhythmia: HCN Channels, 127 CiRCulation 1986, 1993 (2013).

${ }^{256}$ Autism Fact Sheet, supra note 53. 
from suffering disabilities; and

c) Regard extending the lives of people with disabilities and extending the lives of people without disabilities as equally choiceworthy.

QALY-based methods achieve the first two goals, but not the third. ${ }^{257}$ Switching to a simple life year method achieves the first and last goal, but not the second.

As an alternative, I propose adopting a multidimensional measure of costeffectiveness, which treats life extension and quality improvement as independent but relevant factors, rather than combining them into a single measure. Call this the LYAQ (life years and quality) method. To illustrate, under the LYAQ method, extending the length of someone's life by thirty years at a cost of $\$ 300,000$ would have a cost-perlife-year of $\$ 10,000$. Improving the quality of someone's life by curing or preventing blindness would also have a value, say $\$ 50,000$. But, once blindness is cured or prevented, the fact that the person whose life is extended is sighted rather than blind is not used as a "weighting" factor in assessing the value of the intervention.

The LYAQ method does not treat an extra year of life for an older person as less important, as an age-weighted view does, nor does it treat an extra year of life for a disabled person as less important, as the QALY view does. Rather, it treats an extra year of life as equally important for everyone, but gives priority to those who can receive more future life from a given treatment: its aim is to get the greatest "bang for the buck," to employ medical resources in a way that extends life as much as possible. The reason for giving the older or more disabled person lower priority, on the forwardlooking view, is not that they have enjoyed more past life or that the future life they gain will be of a lower quality; rather, it is that their age or disability prevents them from gaining as much future life from the treatment. A younger or less disabled person with a limited life expectancy would receive the same treatment, on the forwardlooking view, as someone whose limited life expectancy is caused by age or disability.

The LYAQ method has some counterintuitive features. In particular, this method treats an intervention that cures blindness as equally important regardless of whether treatment will allow a patient to enjoy full vision for a lifetime or only for a few years. However, these features seem necessary to prevent disability discrimination. Furthermore, there are empirical reasons to believe that the primary harm of disability comes during the period of adaptation to disability, rather than through ongoing disability. ${ }^{258}$ The LYAQ approach captures this phenomenon. It also does a better job of responding to the potential incommensurability of length and quality.

This method could be brought closer to traditional cost-effectiveness analysis, while still minimizing the disadvantage to disabled individuals, by only counting additional years of life as valuable if keeping a patient alive in that condition would not constitute medical futility. This unit might be called a "non-futile life year" (NFLY). Shifting from a QALY to a NFLY metric would capture one part of what is valuable about considering quality, while avoiding discrimination against people with disabilities such as blindness or mobility impairment. It would also base prioritysetting decisions on a concept-medical futility - that is accepted by legal decision makers. ${ }^{259}$ The NFLY proposal resembles the medical ethicist Frances Kamm's

\footnotetext{
${ }^{257}$ For a recognition of this limitation, see Paul Menzel, How Should What Economists Call "Social Values" Be Measured?, 3 J. ETHICS 249, 260 (1999) (labeling this problem the "QALY trap").

${ }^{258}$ See, e.g., John Bronsteen et al., Hedonic Adaptation and the Settlement of Civil Lawsuits, 108 COLUM. L. REV. 1516, 1529-30 (2008).

259 See TeX. HEAlth \& SAFETY CODE ANN. $\$ 166.046$ (West 2010) (delineating procedures for stopping futile treatments); Thaddeus Mason Pope, Dispute Resolution Mechanisms for Intractable Medical Futility Disputes, 58 N.Y.L. SCH. L. REV. 347, 362 (2014). But see Meir Katz, When is Medical Care
} 
suggestion that what matters is not quality-adjusted life years, but what she calls "adequate conscious life." 260

\section{B. AGE-WEIGHTING}

Despite the rhetoric about "death panels" and "killing Grandma" that accompanied the ACA's introduction, surveys of the public systematically show an endorsement of the view that, all else equal, younger individuals should receive some priority over older individuals when scarce interventions are at stake. ${ }^{261}$

There is no existing law that categorically prevents providers from engaging in age weighting when setting priorities, and the public preferences suggest that age weighting has broad popularity. ${ }^{262}$ Additionally, age weighting does not obviously involve a self-serving bias: while not everyone will develop a particular disability or illness, almost everyone will live through different stages of life. ${ }^{263}$ This counsels in favor of an interpretation of the ACA that permits medical providers to engage in age weighting, particularly when the interventions at stake-as with organs for transplantation-are absolutely scarce. ${ }^{264}$

What has explained resistance to age weighting in priority-setting debates? One of the clearest explanations involves a problem that the noted medical ethicist Norman Daniels identified more than twenty years ago: losses for older patients due to age weighting are not always converted into gains for younger patients. ${ }^{265}$ Rather, age weighting might be used to generate surpluses of money that are used in the private sector to increase health insurers' profits or in the public sector to pursue other priorities such as military spending. The possibility that healthcare losses for some will not translate into greater access for others, but instead be siphoned off to projects outside the healthcare system, explains why "saying no to patients in the United States is so hard."266

However, the ACA's provisions help to reduce the risk that age weighting will be used to bolster military spending or increase health insurers' profits. Most prominently, the ACA requires that health insurers return excess revenue to plan subscribers rather than retaining it as profit. ${ }^{267}$ This provision makes healthcare more like the "closed system" that Daniels discusses, ${ }^{268}$ and makes age weighting less objectionable than it hitherto would have been, though not necessarily unobjectionable.

"Futile"? The Institutional Competence of the Medical Profession Regarding the Provision of LifeSustaining Medical Care, 90 NEB. L. REV. 1, 7 (2011).

${ }^{260}$ KAMM, supra note 104 , at 236.

${ }^{261}$ See Paul Dolan et al., QALY Maximisation and People's Preferences: A Methodological Review of the Literature, 14 HEALTH ECON. 197, 201-02 (2005); Olof Johansson-Stenman et al., Saving Lives Versus Life-Years in Rural Bangladesh: An Ethical Preferences Approach, 20 HEALTH ECON. 723, 729 (2011).

${ }^{262}$ Aki Tsuchiya et. al., Measuring People's Preferences Regarding Ageism in Health: Some Methodological Issues and Some Fresh Evidence, 57 SOC. SCI. \& MED. 687, 688 (2003).

${ }^{263}$ See DANIELS, supra note 102, at 85; cf. Persad et al., supra note 11, at 425.

${ }^{264}$ Contra Jessica Dunsay Silver, From Baby Doe to Grandpa Doe: The Impact of the Federal Age Discrimination Act on the 'Hidden' Rationing of Medical Care, 37 CATH. U. L. REV. 993, 1066-67 (1988) (rejecting the use of age in organ allocation).

${ }^{265}$ Norman Daniels, Why Saying No to Patients in the United States Is So Hard: Cost Containment, Justice, and Provider Autonomy, 314 NEW ENG. J. MED. 1380, 1380-81 (1986); see also Leonard M. Fleck, Just Health Care Rationing: A Democratic Decisionmaking Approach, 140 U. PA. L. REV. 1597, 1626 (1992).

${ }^{266}$ Daniels, supra note 265 , at 1380.

${ }^{267} 42$ U.S.C. $\$ 300 \mathrm{gg}-18$ (b)(1) (2012).

${ }^{268}$ Daniels, supra note 265 , at 1381-83. 


\section{FAIRNESS to DIVERSE SEGMENTS OF THE POPULATION}

The ACA presents healthcare policymakers with an opportunity to consider, in greater depth, the equity of how benefits are distributed. QALY-based approaches have traditionally looked at the total health impact on the population when calculating cost-per-QALY figures, rather than considering who receives the health benefits from specific interventions. ${ }^{269}$ As the health economist John Mullahy notes, this means that QALY approaches are insensitive to different interventions' effects on health inequalities between individuals or groups, so long as the total number of QALYs under each policy is the same. ${ }^{270}$

I have argued above that priority-setting approaches that favor individuals whose diseases happen to be cost-effectively treatable are not unfair. ${ }^{271}$ Disease status is not an inappropriate basis for medical judgments, nor are individuals with specific diseases considered members of protected classes for legal purposes. In contrast, priority setting should aim to be fair to individuals from diverse groups within a population: if prostate cancer and colon cancer treatments are equally good from a cost-per-QALY perspective, but prostate cancer treatments provide health benefits only to men, the ensuing disparity in benefits between the sexes seems relevant. The same is true for treatments that have disparate benefits for particular racial or ethnic groups.

Ultimately, rather than solely focusing on total population health, a more complete priority-setting metric would consider health inequalities as well. The adoption of a more complete measure would parallel, for example, the decision to deemphasize antigen matching criteria for kidney transplantation, which helped to drastically reduce the extent that black patients are disadvantaged when seeking organ transplants. ${ }^{272}$

\section{CONCLUSION}

Thinking seriously about priority-setting challenges within the ACA's reimagined vision of American healthcare suggests the possibility of a more pluralistic vision of healthcare, where some choose plans that prevent imminent death at any cost while others choose plans that spend more heavily on cost-effective care. By retaining a private insurance system rather than transitioning to a single-payer system like the British National Health Service, the healthcare reform efforts that culminated in the ACA left open the possibility that different health plans could cater to the heterogeneous preferences of different members of the public. ${ }^{273}$

Ultimately, my verdict on the ACA's effect on priority setting is mixed. The provisions I discussed have the potential to be deeply consequential: they cannot be easily circumvented by advocates of traditional, technocratic cost-effectiveness

\footnotetext{
${ }^{269}$ John Mullahy, Live Long, Live Well: Quantifying the Health of Heterogeneous Populations, 10 HEALTH ECON. 429, 430 (2001).

${ }^{270} I d$. at 435 .

${ }^{271}$ See supra Part II.C. 3.

${ }^{272}$ Coleman, supra note 10, at 1122 ("For example, the system does not rely on HLA antigen matching for kidney transplantation, in part because such an approach would systematically favor white over black organ recipients."); see also Erin C. Hall et al., Effect of Eliminating Priority Points for HLA-B Matching on Racial Disparities in Kidney Transplant Rates, 58 AM. J. KIDNEY DISEASES 813, 813 (2011); cf. Ian Ayres et al., Unequal Racial Access to Kidney Transplantation, 46 VAND. L. REV. 805, $843-50$ (1993) (suggesting how kidney allocation protocols might be revised to remedy racial disparities in allocation)

${ }^{273}$ Cf. EZEKIEL J. EMANUEL, THE ENDS OF HUMAN LifE: MEDICAL ETHICS IN A LiBERAL POLITY 178 244 (1991) (proposing a healthcare system that includes a variety of "community health programs" catering to individuals with different values).
} 
analysis, as some have asserted. As such, they are potentially dangerous: to the extent that they promote a view that considerations of cost and effectiveness are completely outweighed by the gain of even a moment of life, they threaten the possibility of achieving the healthcare system we need-one that supports public health while reining in rising costs. But they also offer the possibility of breaking through a standoff between technocrats and social conservatives, with the former clinging to oversimplified measures like the QALY while the latter criticize any consideration of cost when lives are at stake. Taking seriously the challenge that the ACA's provisions pose requires a health care system that does justice to the complexity of our values. 